\title{
Measurement of Liquid Film Thickness in Micro Tube Annular Flow
}

\author{
Youngbae Han $^{a^{*}}$, Hiroshi Kanno ${ }^{\mathrm{b}}$, Young-Ju Ahn ${ }^{\mathrm{a}}$ and Naoki Shikazono ${ }^{\mathrm{b}}$ \\ ${ }^{a}$ Hongik University Sejong Campus, Sejong-ro 2639, Jochiwon-eup, Sejong city, 339-701, \\ Korea, Tel: $+82-44-860-2766$ \\ ${ }^{\mathrm{b}}$ Institute of Industrial Science, The University of Tokyo, Komaba 4-6-1, Meguro-ku, Tokyo \\ 151-0041, Japan, Tel: +81-3-5452-6776; Fax: +81-3-5452-6776 \\ *Corresponding author: Telephone: +82-44-860-2766. E-mail address: ybhan@hongik.ac.kr (Y. Han)
}

\begin{abstract}
Heat transfer in micro scale two-phase flow attracts large attention since it can achieve large heat transfer area per unit volume. At large flow rate and high quality, annular flow becomes one of the major flow regimes in micro two-phase flow. Heat is transferred by evaporation or condensation of the liquid film, which are the dominant mechanisms of micro scale heat transfer. Therefore, liquid film thickness is one of the most important parameters in modeling the heat transfer phenomena. In the present study, time averaged annular liquid film thickness is measured by laser confocal displacement meter (LCDM), and the gas-liquid interface profile is observed by a high-speed camera. Glass tubes with inner diameters of $D=0.3,0.5$ and $1.0 \mathrm{~mm}$ are used. Degassed water and air are used for working fluids, and the total mass flux is varied from $G=100$ to $500 \mathrm{~kg} / \mathrm{m}^{2} \mathrm{~s}$. Flow patterns are observed and flow pattern map based on Reynolds numbers of gas and liquid flows is suggested. Pressure drop is measured and compared with the prediction using Lockhart and Martinelli parameter. Pressure drop is well predicted with Lockhart-Martinelli correlation. Dimensionless mean film thickness is then plotted against quality, and compared with the annular film model assuming flat gas-liquid interface. Flat interface model overestimated the experimental data. It is considered that the shear stress on the gas-liquid interface in the real annular flow is larger than that estimated in the ideal flat interface model. Prediction using new empirical correlation considering the effect of the non-flat gas-liquid interface showed good agreement with the experiment data.
\end{abstract}




\section{Introduction}

Heat transfer in micro tube attracts large attention since it has many advantages, e.g., high efficiency, miniaturization, and stabilization of gas-liquid interface. In micro tubes, flow characteristics are quite different from those in macro tubes, since surface tension becomes dominant in micro scale. At high quality, annular flow is one of the major flow patterns, and film evaporation or condensation dominates the heat transfer in micro tubes. Therefore, liquid film thickness plays an important role in micro scale heat transfer, and many studies concerned with film thickness and interface profiles in annular flow regimes have been conducted.

Schubring and Shedd (2008) investigated liquid film thickness in horizontal annular airwater flow using the diffused light pattern reflected from the liquid surface. Working fluids were air and water. Glass tubes with inner diameters of $8.8 \mathrm{~mm}$ and $15.1 \mathrm{~mm}$ were used as test tubes. It was reported that the wave velocity of annular film was well correlated by the gas friction velocity. This indicated a direct link between wave velocity and wall shear stress.

Hazuku et al. (2008) measured liquid film thickness in glass tube with inner diameter of 11 $\mathrm{mm}$ using laser confocal displacement meter. The data from this method agreed with that from the image processing method. They concluded that the liquid film thickness decreases due to the density change of the gas phase.

Okawa et al. (2010) also investigated film behavior in annular two-phase flow using laser confocal method. They introduced steam-water two-phase flow in heated SUS tube with inner diameter of $12 \mathrm{~mm}$. They controlled total mass flux and heat flux to produce flow oscillation. They concluded that mean film thickness in the thin film region tends to increase with the decrease of oscillation period.

Revellin et al. (2006) measured flow pattern characteristics in micro tubes with inner diameter of $0.5 \mathrm{~mm}$. Working fluid was R-134a and they applied direct current to heat the 
SUS tube. They measured bubble frequency and superficial vapor velocity by laser light intensity method. In their research, flow patterns and their transitions (bubbly/slug flow/semi-annular flow) were detected by bubble frequency analysis.

Han and Shikazono (2009a) measured liquid film thickness in micro tube slug flow by the confocal method. They used glass tubes with inner diameters of $0.3,0.5,0.7,1.0$ and 1.3 $\mathrm{mm}$ as test tubes. Working fluids were water, ethanol, and FC40. They proposed an empirical correlation for the dimensionless liquid film thickness based on capillary, Reynolds and Weber numbers. They concluded that no inertial force effect is observed at small capillary numbers, while Reynolds number effect becomes apparent at large capillary numbers.

Tibrisa et al. (2010) reviewed measurement methods of liquid film thickness in micro scale. They pointed out that the confocal method allowed dynamic measurements of extremely thin film, and its use should be worth considered for future studies.

Although many researches for liquid film thickness have been carried out, quantitative data of annular liquid film especially in micro scale are still limited. To predict the heat transfer coefficient in micro scale two-phase flow, it is important to clarify the relationship between flow regime and liquid film thickness in micro tube annular flow. In the present study, time averaged liquid film thickness is measured using a confocal method and flow regimes are observed in micro scale annular flow. The relationship between film thickness and flow characteristics is investigated.

\section{Experimental setup and procedures}

The experimental setup used in the present study is shown in Fig. 1. Compressed air and degassed water from the syringe pump were introduced to the inlet block and they were mixed at the T-junction. Then, two-phase gas-liquid mixture was introduced in the test tube. Pressure was measured at the inlet and outlet blocks.

Circular glass tubes with inner diameters of $0.3,0.5$ and $1.0 \mathrm{~mm}$ were used. Length to 
diameter ratio was fixed as $L / D=300$. Both ends of the glass tube were connected to the inlet and outlet blocks. The T-junction in the inlet block is shown in Fig. 2.

Figure 3 shows the test section and the measurement position. The total length $L$ is defined as the distance from the inlet pressure port to the outlet pressure port. Liquid film thickness and flow regime were measured at the position $0.833 \mathrm{~L}$ downstream from the inlet pressure port.

Mass flow controllers (MQV9200, MQV0005, MQV0050, Yamatake) were used to control the gas flow rate, and syringe pump (IP7100, Lab-Quatec) was used to control the liquid flow rate. Liquid was drawn from the reservoir tank through $20 \mathrm{~m}$ or $60 \mathrm{~m}$ filters. Pressure sensors (AP-10S, AP-13S, Keyence) were used to measure the pressure drop of the test tubes.

Air was used for the gas phase and water was used for the liquid phase. All experiments were conducted under the condition of room temperature. Table 1 shows the properties of water and air under atmospheric pressure.

Total mass flux was controlled as $G=100,300$ and $500 \mathrm{~kg} / \mathrm{m}^{2} \mathrm{~s}$. The ratio of gas mass flow rate to the total mass flow rate is called flow quality hereafter. Flow quality $x$ and mass flux $G$ are calculated from the mass fluxes of liquid and gas flows as follows:

$$
\begin{aligned}
& x=\frac{\dot{m}_{\mathrm{G}}}{\dot{m}_{\mathrm{G}}+\dot{m}_{\mathrm{L}}} \\
& G=\frac{\dot{m}_{\mathrm{G}}+\dot{m}_{\mathrm{L}}}{A}
\end{aligned}
$$

where $A$ is total flow area. Superficial gas and liquid velocities were calculated with flow quality and mass flow rate as follows:

$$
U_{\mathrm{SG}}=\frac{G \cdot x}{\rho_{\mathrm{G}}}
$$




$$
U_{\mathrm{SL}}=\frac{G \cdot(1-x)}{\rho_{\mathrm{L}}}
$$

where $\rho$ is density. Reynolds numbers based on superficial velocities of liquid and gas flows are expressed as follows:

$$
\begin{aligned}
\operatorname{Re}_{\mathrm{SG}} & =\frac{G \cdot x \cdot D}{\mu_{\mathrm{G}}} \\
\operatorname{Re}_{\mathrm{SL}} & =\frac{G \cdot(1-x) \cdot D}{\mu_{\mathrm{L}}}
\end{aligned}
$$

where $D$ is inner diameter and is viscosity. Table 2 shows the experimental conditions of the present study. In the present experiment, the highest superficial gas velocities are 74.8 , 171.3 and $218.7 \mathrm{~m} / \mathrm{s}$ at $G=100,300$ and $500 \mathrm{~kg} / \mathrm{m}^{2} \mathrm{~s}$, respectively. In Table $2, U_{\mathrm{SG}}$ at the measurement position is calculated using local gas density. Linear pressure drop in the test section is assumed and local pressure is calculated at measurement position. Local gas density is obtained from the local pressure at the measurement position. On the other hand, the highest superficial liquid velocities are $0.089,0.27$ and $0.424 \mathrm{~m} / \mathrm{s}$ at $G=100,300$ and $500 \mathrm{~kg} / \mathrm{m}^{2} \mathrm{~s}$, respectively. Figure 4 shows the range of Reynolds numbers based on superficial velocities of liquid and gas flows for all the experimental conditions. The highest $\operatorname{Re}_{\mathrm{SG}}$ is 26,280 at $x=0.958$ and $G=500 \mathrm{~kg} / \mathrm{m}^{2} \mathrm{~s}$ in the tube of $D=1.0 \mathrm{~mm}$ diameter. The highest $\mathrm{Re}_{\mathrm{SL}}$ is 422.7 at $\mathrm{x}=0.153$ and $G=500 \mathrm{~kg} / \mathrm{m}^{2} \mathrm{~s}$ also in the tube of $D=1.0 \mathrm{~mm}$ diameter.

Laser confocal displacement meter (LT9010M, Keyence) was used to measure the liquid film thickness. This method was used in the previous studies (Han and Shikazono, 2009a,b). It was reported that the laser confocal displacement meter could measure the liquid film thickness very accurately within $1 \%$ error (Hazuku et al., 2005). The resolution for the present laser confocal displacement meter is $0.01 \mathrm{~m}$ and the spot diameter of the laser is 2 m. Sampling frequency is $1 \mathrm{kHz}$. 5000 data points for 5 seconds were collected for each run. Dimensionless mean film thickness was plotted against quality for each diameter tube. 
Flow pattern was observed by using high-speed camera (SA1.1, Photron). Frame rate was 20000 frames per second with a shutter time of 5.3 s. Figure 5 shows the cross section of the measuring point. To remove the outer-wall curvature effect, two glass slides were put on both sides of the glass tube and glycerol is filled in between them. The refractive index of glycerol is almost same as that of the Pyrex glass. Therefore, the outer-wall curvature effect can be removed and inner-liquid surface can be visualized clearly.

\section{Results and Discussions}

\subsection{Flow patterns}

Two-phase flow patterns were observed against quality at a fixed mass flux condition. At the quality $x=0$, flow is a single-phase liquid flow. Mass flux of the liquid flow decreases and mass flux of the gas flow increases so that total mass flux is kept constant. Flow pattern becomes slug flow at very low quality. As quality increases, the gas velocity becomes very fast due to the low density of gas compared with that of liquid, and flow pattern becomes annular flow. Finally, flow becomes single-phase gas flow at quality $x=1$.

\subsubsection{Effect of quality}

Figure 6 shows the flow patterns for $D=0.5 \mathrm{~mm}$ tube at $G=300 \mathrm{~kg} / \mathrm{m}^{2} \mathrm{~s}$. At low quality, annular flow with liquid ring appears as shown in Fig. 6 (a). Liquid ring appears regularly and flows much faster than the liquid film. In some cases, liquid ring appears irregularly. This flow pattern was reported by many previous researches as different terms such as slugannular flow, gas core flow with ring-shaped liquid film and liquid ring flow (Wang et al., 2012; Kawahara et al., 2002; Serizawa et al., 2002). Liquid ring becomes smaller as quality increases. As quality further increases, liquid ring disappears and flow pattern becomes annular with wavy interface. Ripples on the gas-liquid interface are observed as shown in Fig. 6 (d). At moderate quality, two kinds of flow patterns, i.e. annular-ring flow and annular-ripple flow, appear alternatively.

\subsubsection{Effect of mass flux}


Figure 7 shows flow patterns for $D=0.5 \mathrm{~mm}$ and $x=0.45$ against different total mass fluxes. At $G=100 \mathrm{~kg} / \mathrm{m}^{2} \mathrm{~s}$, the gas velocity is still low and flow pattern is annular-ring flow. As mass flux increases, annular-ring and annular-ripple flows appear alternatively as shown in Fig. 7 (b). At $G=500 \mathrm{~kg} / \mathrm{m}^{2} \mathrm{~s}$, flow pattern becomes annular flow with large waves, which is different from that of the annular-ripple flow. This flow pattern is similar to churn flow in a macro tube. We call this flow pattern annular-wavy flow.

Reynolds numbers based on superficial gas velocity of the three cases in Fig. 7 are 1233, 3769 and 6050, respectively. As mass flux increases, flow transition from laminar to turbulent occurs in gas flow. However, Reynolds number of liquid flow is much lower than that of gas flow. Liquid flow remains in the laminar Re range in all the present experimental conditions. It is considered that the turbulent gas flow generates ripples or waves on the liquid film.

\subsubsection{Effect of tube diameter}

Figure 8 shows flow patterns for $G=300 \mathrm{~kg} / \mathrm{m}^{2}$ s and $x=0.45$ in three different diameter tubes. As tube diameter is increased, flow pattern changes from annular-ring flow to annular-wavy flow as shown in Fig. 8. Reynolds number of gas flow increases with tube diameter and this results in the wavy surface on the liquid film. Reynolds numbers based on gas superficial velocity of the three cases in Fig. 8 are 2150, 3769 and 7515, respectively. Surface tension force is also weakened in the larger diameter tubes, and the gas-liquid interface becomes much more wavy.

\subsubsection{Flow pattern map}

Figure 9 shows flow pattern map based on Reynolds numbers of liquid and gas flows. Flow pattern becomes annular-ring flow at low gas Reynolds number. As gas Reynolds number increases larger than roughly 3000, flow pattern changes from annular-ring flow to other flow patterns. It is considered that the flow pattern change is attributed to the laminar to turbulent transition in the gas flow. 
On the other hand, liquid Reynolds number is lower than 500 for all the experimental data. At very low liquid Reynolds number, flow pattern directly changes from annular-ring flow to annular-ripple flow. As liquid Reynolds number increases at high gas Reynolds number, flow pattern changes from annular-ring flow to annular-wavy flow.

\subsection{Pressure drop}

In two-phase flow, Lockhart and Martinelli correlation is widely used to predict the pressure drop (Lockhart and Martinelli, 1949). Two-phase frictional pressure drop is predicted with a two-phase multiplier for the liquid-phase or the gas-phase as follows:

$$
\begin{aligned}
& \Delta P_{\mathrm{T}}=\Delta P_{\mathrm{L}} \cdot \Phi_{\mathrm{L}}^{2} \\
& \Delta P_{\mathrm{T}}=\Delta P_{\mathrm{G}} \cdot \Phi_{\mathrm{G}}^{2}
\end{aligned}
$$

where $P_{\mathrm{T}}$ is total pressure drop. $P_{\mathrm{L}}$ and $P_{\mathrm{G}}$ are pressure drops assuming that liquid or gas alone is flowing inside the tube. Pressure drops $P_{\mathrm{L}}$ and $P_{\mathrm{G}}$ can be calculated as follows:

$$
\begin{aligned}
& \Delta P_{\mathrm{G}}=\left(\frac{L}{(D)}\right)^{4} f_{\mathrm{G}} \frac{G^{2} x^{2}}{2 \rho_{\mathrm{G}}} \\
& \Delta P_{\mathrm{L}}=\left(\frac{L}{(D)}\right)^{4} f_{\mathrm{L}} \frac{G^{2} x^{2}}{2 \rho_{\mathrm{L}}}
\end{aligned}
$$

where $f$ is the Fanning friction factor and is expressed according to flow regimes as follows:

$$
\begin{gathered}
f=16 / \operatorname{Re}(\text { Laminar, } \operatorname{Re}<2300) \\
f=0.079 / \operatorname{Re}^{0.25}(\text { Turbulent, } \operatorname{Re} \geq 2300)
\end{gathered}
$$

Reynolds numbers of liquid and gas flows can be calculated as Eqs. (5) and (6). Two-phase multipliers $\Phi_{\mathrm{L}}^{2}$ and $\Phi_{\mathrm{G}}^{2}$ are calculated as follows: 


$$
\begin{aligned}
& \Phi_{\mathrm{G}}^{2}=1+C X+X^{2} \\
& \Phi_{\mathrm{L}}^{2}=1+\frac{C}{X}+\frac{1}{X^{2}}
\end{aligned}
$$

where $C$ is Lockhart-Martinelli constant. The values of $C$ which depend on the flow regimes are listed in Table 3. Lockhart-Martinelli parameter $X$ is defined as the ratio of pressure drops $P_{\mathrm{L}}$ and $P_{\mathrm{G}}$ :

$$
X=\sqrt{\Delta P_{\mathrm{L}} / \Delta P_{\mathrm{G}}}
$$

In the present study, the gas velocity becomes very large and the inlet pressure of test section also increases up to several bars. Therefore, pressure drop of gas phase should be calculated with taking compressibility into account as follows:

$$
\left.\frac{d P}{d z}\right|_{\mathrm{G}}=\frac{4 f_{\mathrm{G}}}{D} \cdot \frac{(G \cdot x)^{2}}{\rho_{\mathrm{G}}^{\prime}}
$$

where $\rho_{\mathrm{G}}{ }^{\prime}$ is the density of the compressible air. Assuming an ideal gas, gas density can be written as follows:

$$
\rho_{\mathrm{G}}^{\prime}=\rho_{\mathrm{G}} \frac{P}{P_{\mathrm{a}}}
$$

where $P_{\mathrm{a}}$ is the atmospheric pressure and $\rho_{\mathrm{G}}$ is the air density at the atmospheric pressure. In the present study, the averaged value between inlet and outlet air densities is used. Pressure drop assuming that the gas alone is flowing inside the tube, $P_{\mathrm{G}}$ is modified from Eq. (9) as follows: 


$$
\Delta P_{\mathrm{G}}=\left(\frac{L}{(}\right) 4 f_{\mathrm{G}} \frac{G^{2} x^{2}}{2 \rho_{\mathrm{G}}} \cdot \frac{2 P_{\mathrm{a}}}{P_{\mathrm{a}}+P_{\mathrm{in}}}
$$

where $P_{\text {in }}$ is the inlet pressure. Pressure drop assuming that the liquid alone is flowing inside the tube, $P_{\mathrm{L}}$ is calculated from Eq. (10). Lockhart-Martinelli parameter $X$ is calculted from $P_{\mathrm{G}}$ and $P_{\mathrm{L}}$ as Eq. (15). Two-phase multipliers $\Phi_{\mathrm{L}}^{2}$ and $\Phi_{\mathrm{G}}^{2}$ are calculated from Lockhart-Marinelli parameter $X$ and constant $C$ according to the gas and liquid flow regimes as Eqs. (13) and (14). Total pressure drop $P_{\mathrm{L}}$ is calcualted as Eqs. (7) and (8).

Figure 10 shows the comparison between measured and predicted pressure drops in the $D=$ $0.5 \mathrm{~mm}$ tube. Solid symbols are the measured pressure drop, and each line represents the predicted pressure drop. Pressure drop increases with quality and starts to decrease after taking a maximum at around $x=0.9$. As mass flux increases, pressure drop also increases due to the higher flow velocity. Predicted pressure drop also increases with quality and starts to decrease at around $x=0.9$. The flow regime of gas flow at $G=500 \mathrm{~kg} / \mathrm{m}^{2} \mathrm{~s}$ is turbulent for all the experimental data. Due to the difference in friction factors between laminar and turbulent flows, discontinuous change is observed in the prediction lines for $G$ $=100$ and $300 \mathrm{~kg} / \mathrm{m}^{2} \mathrm{~s}$.

Figure 11 shows the comparison between measured and predicted pressure drops for all the experimental data. As shown in Fig. 10, predicted pressure drop shows relatively good accordance with measured pressure drop within the range of $\pm 50 \%$. The standard deviation of the prediction to the experimental data is $25.5 \%$

\subsection{Liquid film thickness}

\subsubsection{Measurement of liquid film thickness}

Figure 12 shows measured liquid film thickness in the $D=0.5 \mathrm{~mm}$ tube at $G=300 \mathrm{~kg} / \mathrm{m}^{2} \mathrm{~s}$ and $x=0.46$. In the present liquid film thickness measurement, sampling frequency is 1 $\mathrm{kHz}$ and 5000 data points for 5 seconds are collected for each run. The gas-liquid interface shape changes much faster than the measuring frequency. Thus, its profile changes during 
the measurement sampling time of $1 \mathrm{~ms}$. Therefore, the measured liquid film thickness data are averaged as a representative value during the $1 \mathrm{~ms}$ sampling time as shown in Fig. 12.

Although the instantaneous time variation of the gas-liquid interface profile cannot be obtained, the time averaged value of the measured liquid film thickness provides useful information to understand the features of liquid film and to predict mean heat transfer characteristics in micro tube annular flow. In the present study, 5000 data points are used to take the average of the liquid film thickness. For example, mean liquid film thickness in Fig. 12 becomes $11.7 \mathrm{~m}$.

Figure 13 shows the mean liquid film thickness against quality in the $D=1.0 \mathrm{~mm}$ tube. As quality increases, mean liquid film thickness decreases due to the increase of gas velocity. Mean liquid film thickness shows a large decrease at low quality. However, this trend becomes gentle as quality is increased. It is considered that the change of the decrease rate of mean liquid film thickness is attributed to the change of the flow pattern.

Flow pattern is annular-ring flow in the low quality condition. As quality is increased at low quality, the size of liquid-ring becomes smaller which results in the decrease of liquid film thickness. As quality is further increased, flow pattern changes from annular-ring flow to annular-ripple flow or annular-wavy flow. In these flows, liquid film thickness is affected by the gas-liquid wavy interface rather than the liquid-ring. As mass flux increases, mean liquid film thickness decreases at the same quality. The velocity of gas flow is higher at larger mass fluxes, and the transition of flow pattern occurs earlier.

\subsubsection{Comparison with theoretical liquid film thickness}

Figure 14 shows the schematic of force balance in a micro tube assuming that the gas-liquid interface is flat. Pressure drops in both liquid film and gas flow are the same. Force balance equations in liquid film and gas flow are as follows:

$$
\begin{gathered}
2 \pi(R-\delta) \cdot d z \cdot \tau_{i}-2 \pi R \cdot d z \cdot \tau_{w}=\pi\left(R^{2}-(R-\delta)^{2}\right) d F \\
-2 \pi(R-\delta) \cdot d z \cdot \tau_{i}=\pi(R-\delta)^{2} \cdot d F
\end{gathered}
$$


where $\tau_{i}$ is the shear stress on the gas-liquid interface, and $\tau_{w}$ is the shear stress on the tube wall. Dimensionless liquid film thickness $\delta / R$ can be calculated from Eqs. (19) and (20) as follows:

$$
\frac{\delta}{R}=1-\frac{\tau_{i}}{\tau_{w}}
$$

Dimensionless liquid film thickness is determined by the ratio between the interface shear stress and the wall shear stress. If quality is close to zero, the velocity of gas flow is very small, so the interface shear stress becomes almost zero. The right hand side of Eq. (21) becomes unity and liquid film thickness becomes $R$, i.e the flow is almost identical to the liquid single-phase flow. On the contrary, if quality is close to unity, the liquid velocity is very low and liquid film is almost stationary. The interface shear stress becomes almost the same as the wall shear stress, and the right hand side of Eq. (21) becomes zero. Then, liquid film thickness becomes zero and flow pattern is almost the same as the single-phase gas flow. The interface shear stress and the wall shear stress are calculated as follows:

$$
\begin{aligned}
& \tau_{i}=\frac{1}{2} f_{\mathrm{G}} \rho_{\mathrm{G}} U_{\mathrm{G}}^{2} \\
& \tau_{w}=\frac{1}{2} f_{\mathrm{L}} \rho_{\mathrm{L}} U_{\mathrm{L}}^{2}
\end{aligned}
$$

The velocity in Eq. (22) should be $\left(U_{\mathrm{G}}-U_{\mathrm{L}}\right)$. However, the velocity of the liquid film is negligible compared to the velocity of the gas flow. Thus, the velocity in Eq. (22) is simplified as $U_{\mathrm{G}}$. Friction factors $f_{\mathrm{G}}$ and $f_{\mathrm{L}}$ are calculated according to the flow regimes as follows:

$$
\begin{gathered}
f=16 / \operatorname{Re}(\text { Laminar, } \operatorname{Re}<2300) \\
f=0.079 / \operatorname{Re}^{0.25}(\text { Turbulent, } \operatorname{Re} \geq 2300)
\end{gathered}
$$

The Reynolds number used to calculate friction factors in Eqs. (24) and (25) should be 
different from that in Eqs. (5) and (6). The Reynolds numbers in Eqs. (24) and (25) are based on the diameter of gas flow and the liquid film thickness. The definition of Reynolds numbers in Eqs. (24) and (25) are as follows:

$$
\begin{gathered}
\operatorname{Re}_{\mathrm{GF}}=\frac{\rho_{\mathrm{G}} U_{\mathrm{G}} 2(R-\delta)}{\mu_{\mathrm{G}}} \\
\operatorname{Re}_{\mathrm{LF}}=\frac{\rho_{\mathrm{L}} U_{\mathrm{L}} 2 \delta}{\mu_{\mathrm{L}}}
\end{gathered}
$$

From Eqs. (21)-(23), dimensionless liquid film thickness $\delta / R$ can be calculated as follows:

$$
\frac{\delta}{R}=1-\frac{f_{\mathrm{G}}}{f_{\mathrm{L}}} \cdot \frac{\rho_{\mathrm{G}} U_{\mathrm{G}}^{2}}{\rho_{\mathrm{L}} U_{\mathrm{L}}^{2}}
$$

where $f_{\mathrm{G}} / f_{\mathrm{L}}$ is the ratio between the friction factors in gas and liquid flows. Liquid film flow is laminar for all the experimental conditions. Therefore, $f_{\mathrm{G}} / f_{\mathrm{L}}$ is determined according to the flow regime of gas flow as follows:

$$
\left(\frac{f_{\mathrm{G}}}{f_{\mathrm{L}}}\right)= \begin{cases}\frac{\operatorname{Re}_{\mathrm{LF}}}{\operatorname{Re}_{\mathrm{GF}}} & \text { (laminar gas flow) } \\ 0.00494 \frac{\operatorname{Re}_{\mathrm{LF}}}{\operatorname{Re}_{\mathrm{GF}}^{0.25}} & \text { (turbulent gas flow) }\end{cases}
$$

To predict the liquid film thickness, liquid film thickness $\delta$ is assumed first. Reynolds numbers, $\mathrm{Re}_{\mathrm{LF}}$ and $\mathrm{Re}_{\mathrm{GF}}$, are determined from the assumed liquid film thickness. The ratio of friction factor $f_{\mathrm{G}} / f_{\mathrm{L}}$ is determined from Eq. (29). Liquid film thickness is re-calculated from the ratio of friction factor $f_{\mathrm{G}} / f_{\mathrm{L}}$ and compared with the initially assumed liquid film thickness. Gas compressibility due to high inlet pressure is also taken into account to calculate Eqs. (26)-(29). Liquid film thickness can be obtained by iteratively solving Eqs. (26)-(29). 
Figure 15 shows the predicted dimensionless mean film thickness against quality using Eqs. (26)-(29). Under the same properties, prediction values should follow the same line in laminar flow regardless of mass flux. However, prediction values are slightly different due to the different air densities caused by gas compressibility. Prediction lines show quick decrease at different qualities for different mass fluxes since friction factor is discontinuous at laminar to turbulent transition Reynolds number.

Prediction overestimates the dimensionless mean film thickness for all conditions. The difference between the prediction and the measurement values is larger at smaller quality. As quality increases, the difference decreases. Prediction value is obtained under the assumption that the gas-liquid interface is flat. However, the gas-liquid interface is not flat in reality. Liquid ring, ripples or wavy surface appears on the gas-liquid interface. Therefore, the shear stress on the real rough gas-liquid interface $\tau_{i}$ should be larger than that on the flat one. It is obvious from Eq. (21) that liquid film thickness decreases when $\tau_{i}$ increases. At higher quality, the liquid film gets thinner and the gas-liquid interface roughness decreases. This is considered to be the reason for small difference between the prediction and the measured values at higher quality.

At the same mass flux, the dimensionless mean film thickness decreases as the tube diameter is increased. The gas velocities in the tubes of three different diameters are the same at the same mass flux. However, Reynolds numbers are different. The gas flow becomes more stable at lower Reynolds number and the gas-liquid interface is expected to be more flat. Surface tension effect in smaller diameter tube is stronger, and this also makes the gas-liquid interface stable. Therefore, the dimensionless mean film thickness in the smaller diameter tube becomes larger.

Figure 16 shows the comparison between the experimental data and the prediction values using Eqs. (26)-(29). Prediction overpredicts the experimental data by more than 50\%. Prediction values are obtained under the assumption that the gas-liquid interface is perfectly flat. However, in the real two phase flow, the gas-liquid interface is not flat due to liquid ring, ripples and wavy surface. The shear stress on the interface should be modified to predict the liquid film thickness more accurately. The shear stress on the wall is also affected by non-flat gas-liquid interface. Therefore, the ratio between the friction factors in 
gas and liquid flows, $f_{\mathrm{G}} / f_{\mathrm{L}}$ are modified. The constants and exponents are determined to minimize the square sum $S$ :

$$
S=\sum\left[\ln \frac{\left((\delta / D)_{\mathrm{pre}}\right)}{\left.(\delta / D)_{\text {exp }}\right)}\right]^{2}
$$

The ratio between the friction factors considering the non-flat interface effect is obtained empirically from the current experimental data as:

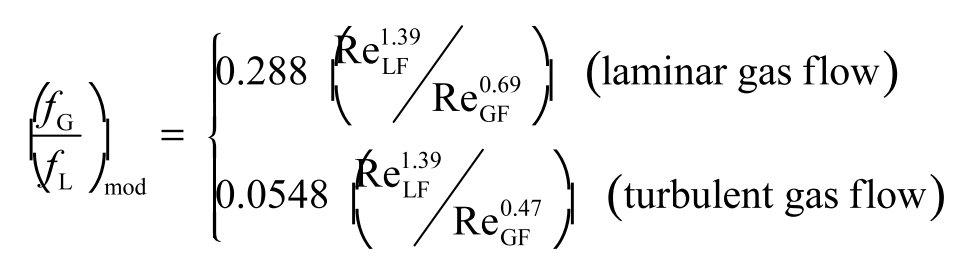

Figure 17 shows the predicted dimensionless mean film thickness with the modified friction factor ratio, Eq. (31), against quality. Predicted dimensionless mean film thickness shows good agreement with the experimental data. In addition, discontinuity in prediction line due to flow transition from laminar to turbulent does not appear in the prediction, because friction factors are correlated using continuous experimental data. Prediction values with the modified friction factor ratio show good agreement with the experimental data within the range of $\pm 50 \%$, as shown in Fig. 18 .

Figure 19 shows the comparison between the original friction factor ratio and the modified friction factor ratio against quality in the $D=0.5 \mathrm{~mm}$ tube. Modified friction factor ratio is much higher than the original friction factor ratio in the low quality region. As quality increases, difference decreases and modified friction factor ratio becomes almost the same with the origineal friction factor ratio.

Gas velocity becomes very high at high flow quality. Liquid film becomes very thin at such high flow quality conditions. Therefore, gas-phase flow in a micro tube is close to a single phase flow with roughness. In the present experiment, gas flow at the measurement position 
is always in the subsonic range. Thus, difference between modified $\left(f_{\mathrm{G}} / f_{\mathrm{L}}\right)$ and original $\left(f_{\mathrm{G}} / f_{\mathrm{L}}\right)$ at high gas velocities in Fig. 19 is considered to be due to the roughness effect of the interface.

Large difference in the friction factor ratio at low quality region can be attributed to the liquid ring in annular-ring flow. In the captured flow pattern movies, liquid rings are generated frequently in larger mass flux. Difference in the friction factor ratio becomes larger as mass flux increases. Due to the limitation of the present experimental setup, instantaneous shape or thickness of liquid ring could not be measured in the present study. To develop more accurate model for the liquid film thickness in micro tube annular flow, it is necessary to investigate the amplitude, frequency and other features on the liquid ring. This will be investigated in the future work.

\section{Concluding Remarks}

Liquid film thickness in micro tube annular flow is measured by laser confocal displacement meter. Three kinds of flow patterns, i.e. annular-ring flow, annular-ripple flow and annular-wavy flow, are observed. In some cases, two kinds of flow patterns appear alternatively. Flow patterns are classified well by Reynolds numbers based on the superficial gas and liquid velocities. Pressure drop is compared with the prediction of Lockhart and Martinelli correlation. Lockhart and Martinelli correlation predicts pressure quite well with using the changed air density caused by gas compressibility. The dependence of dimensionless mean film thickness on quality is investigated under various experimental conditions. Dimensionless mean film thickness decreases with the increase of mass flux and tube diameter. From the force balance of the liquid film and the gas flow, dimensionless mean film thickness is determined by the ratio between the interface and the wall shear stresses. Prediction assuming flat gas-liquid interface overestimates dimensionless mean film thickness. The ratios between friction factors considering the nonflat interface effect are suggested empirically from the current experimental data. Predicted values with the modified friction factor ratios show good accordance with the experimental data within the range of $\pm 50 \%$. 


\section{ACKNOWLEDGEMENT}

This work was partly supported by 2013 Hongik University Research Fund and by JST ALCA program "Development of Trilateral steam cycle for waste heat recovery.

\section{REFERENCES}

Han, Y., Shiakzono, N., 2009a, Measurement of the liquid film thickness in micro tube slug flow, Int. J. Heat Fluid Flow 30, 842-853.

Han, Y., Shiakzono, N., 2009b, Measurement of the liquid film thickness in micro square channel, Int. J. Multiphase Flow 35, 896-903.

Hazuku, T., Takamasa, T., Matusmoto, Y., 2005, Measurement of liquid film in microchanels using a laser focus displacement meter, Exp. in Fluids 38 (6), 780-788.

Hazuku, T., Takamasa, T., Matsumoto, Y., 2008, Experimental study on axial development of liquid film in a vertical upward annular two-phase flow, Int. J. Multiphase Flow 34, 111127.

Kawahara, A., Chung, P.M.-Y., Kawaji, M., 2002, Investigation of two-phase flow pattern, void fraction and pressure drop in a micro channel, Int. J. Multiphase flow 28, 1411-1435.

Lockhart, R.W., Martinelli, R.C., 1949, Proposed Correlation of Data for Isothermal Twophase Two-Component Flow in Pipes, Chem. Eng. Progress 45, 39-48.

Okawa, T., Goto, T., Yamagoe, Y., 2010, Liquid film behavior in annular two-phase flow under flow oscillation condition, Int. J. Heat Mass Transf. 53, 962-971.

Revellin, R., Dupont, V., Ursenbacher, T., Thome, J., Zun, I., 2006, Conditions of diabatic two-phase flows in microchannels: Flow parameter reslts for R-134a in a $0.5 \mathrm{~mm}$ channel, Int. J. Multiphase Flow 32, 755-774.

Schubring, D., Shedd, T.A., 2008, Wave behavior in horizontal annular air-water flow, Int. 


\section{J. Multiphase Flow 34, 636-646.}

Serizawa, A., Feng, Z., Kawara, Z., 2002, Two-phase flow in microchannels, Exp. Thermal Fluid Sci. 26, 703-714.

Tibriça, C.B., Nascimento, F.J. do, Ribatski, G., 2010, Film thickness measurement techniques applied to micro-scale two-phase flow systems, Exp. Thermal Fluid Sci. 34, 463-473.

Wang, X., Yong, Y., Fan, P., Yu, G., Yang, C., Mao, Z., 2012, Flow regime transition for cocurrent gas-liquid flow in micro-channels, Chem. Eng. Sci. 69, 578-586.

Table 1 Properties of the working fluids under atmospheric pressure

\begin{tabular}{c|c|c|c}
\hline & Temperature $\left[{ }^{\circ} \mathrm{C}\right]$ & Water & Air \\
\hline \hline$\rho\left(\mathrm{kg} / \mathrm{m}^{3}\right)$ & 20 & 998 & 1.204 \\
\hline
\end{tabular}




\begin{tabular}{c|c|c|c}
\hline \multirow{2}{*}{$(\mathrm{Pa} \cdot \mathrm{s})$} & 25 & 997 & 1.184 \\
\cline { 2 - 4 } & 20 & 1001 & 0.1915 \\
\hline \multirow{3}{*}{$\sigma(\mathrm{mN} / \mathrm{m})$} & 20 & 888 & 0.1965 \\
\cline { 2 - 4 } & 25 & 72.7 & - \\
\hline \multirow{2}{*}{$n$} & - & 72.0 & 1.0 \\
\hline
\end{tabular}

Table 2 Experimental conditions in the present study

\begin{tabular}{c|c|c|c|c|c}
\hline$D[\mathrm{~mm}]$ & $G\left[\mathrm{~kg} / \mathrm{m}^{2} \mathrm{~s}\right]$ & $U_{\mathrm{SG}}{ }^{*}[\mathrm{~m} / \mathrm{s}]$ & $U_{\mathrm{SL}}[\mathrm{m} / \mathrm{s}]$ & $\mathrm{Re}_{\mathrm{SG}}$ & $\mathrm{Re}_{\mathrm{SL}}$ \\
\hline 0.3 & 100 & $12.3-45.3$ & $0.085-0.042$ & $251-949$ & $12.7-25.3$ \\
\hline 0.3 & 300 & $23.7-141.8$ & $0.028-0.269$ & $949-4474$ & $8.45-80.3$ \\
\hline 0.3 & 500 & $49.0-150.5$ & $0.047-0.424$ & $1259-7458$ & $14.1-127$ \\
\hline
\end{tabular}




\begin{tabular}{c|c|c|c|c|c}
\hline 0.5 & 100 & $12.3-70.2$ & $0.0085-0.085$ & $420-2512$ & $4.23-42.3$ \\
\hline 0.5 & 300 & $30.0-155.7$ & $0.014-0.258$ & $1166-7861$ & $6.76-129$ \\
\hline 0.5 & 500 & $59.2-226.5$ & $0.026-0.407$ & $2563-13024$ & $12.7-203$ \\
\hline 1.0 & 100 & $9.1-74.8$ & $0.0042-0.089$ & $607-5256$ & $4.23-88.8$ \\
\hline 1.0 & 300 & $25.1-171.3$ & $0.015-0.267$ & $1820-15652$ & $14.8-266$ \\
\hline 1.0 & 500 & $52.2-218.7$ & $0.021-0.424$ & $4195-26281$ & $21.1-423$ \\
\hline
\end{tabular}

* $U_{\mathrm{SG}}$ at the measurement position is calculated using local gas density.

Table 3 The values of Lockhart-Martinelli constant $C$ according to flow regimes

\begin{tabular}{c|c|c}
\hline Liquid phase & Gas phase & $C$ \\
\hline \hline Laminar & Laminar & 5 \\
\hline Turbulent & Laminar & 10 \\
\hline Laminar & Turbulent & 12 \\
\hline
\end{tabular}




\begin{tabular}{l|l|c}
\hline Turbulent & Turbulent & 20 \\
\hline
\end{tabular}

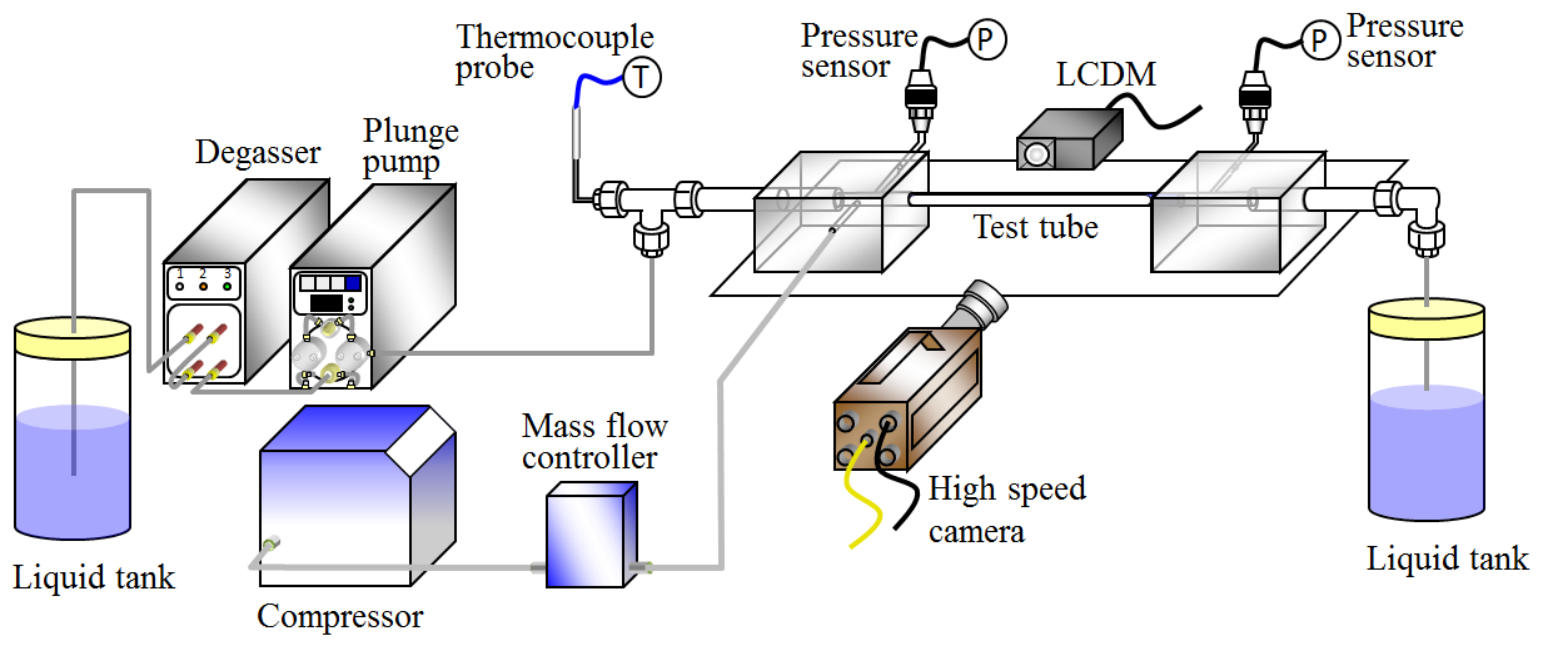

Fig. 1. Schematic of the experimental setup 


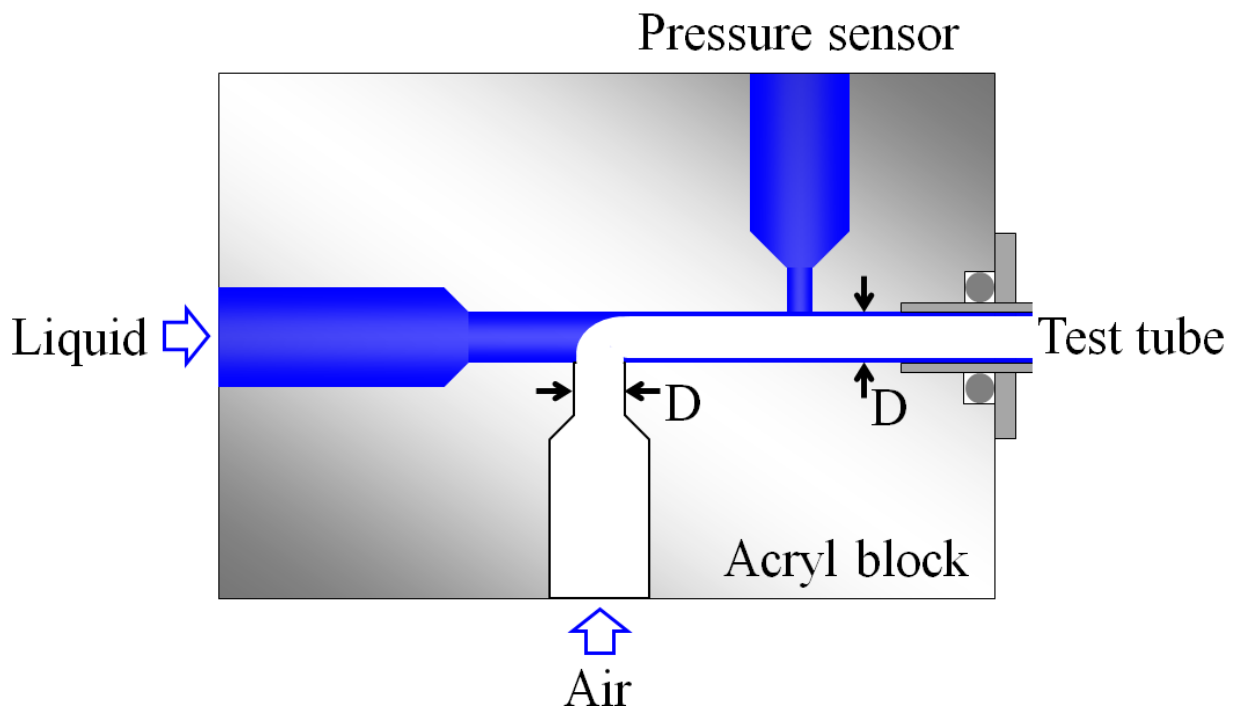

Fig. 2. T-junction in the inlet block 


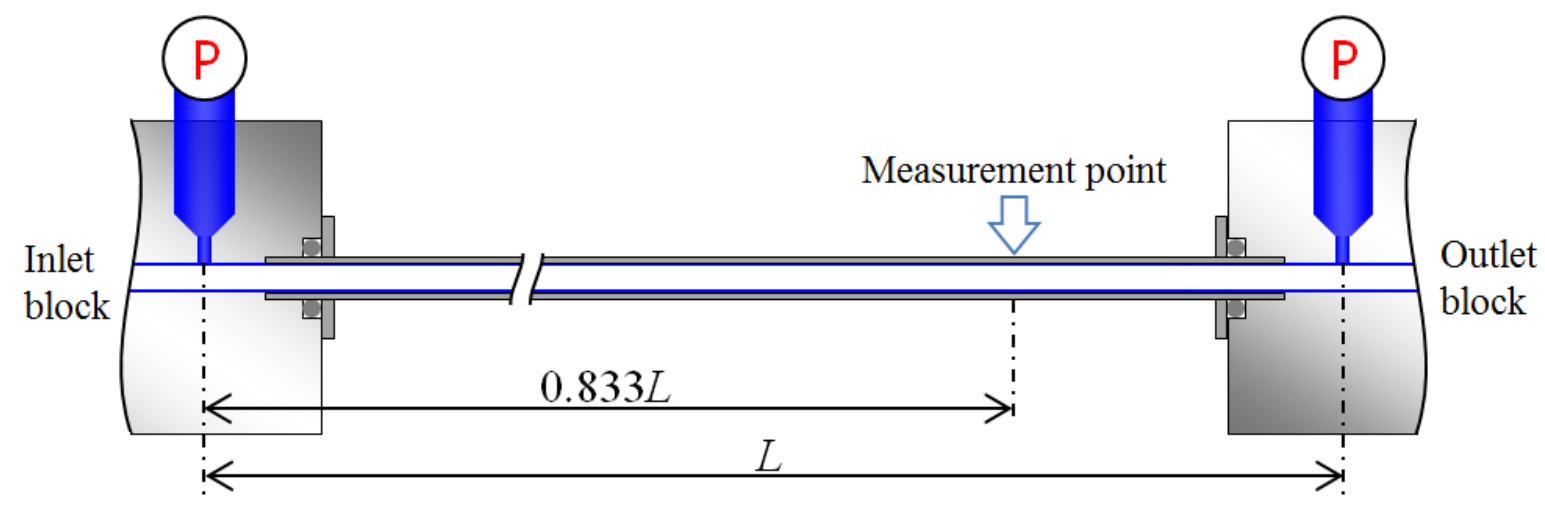

Fig. 3. Test section and the measurement point 


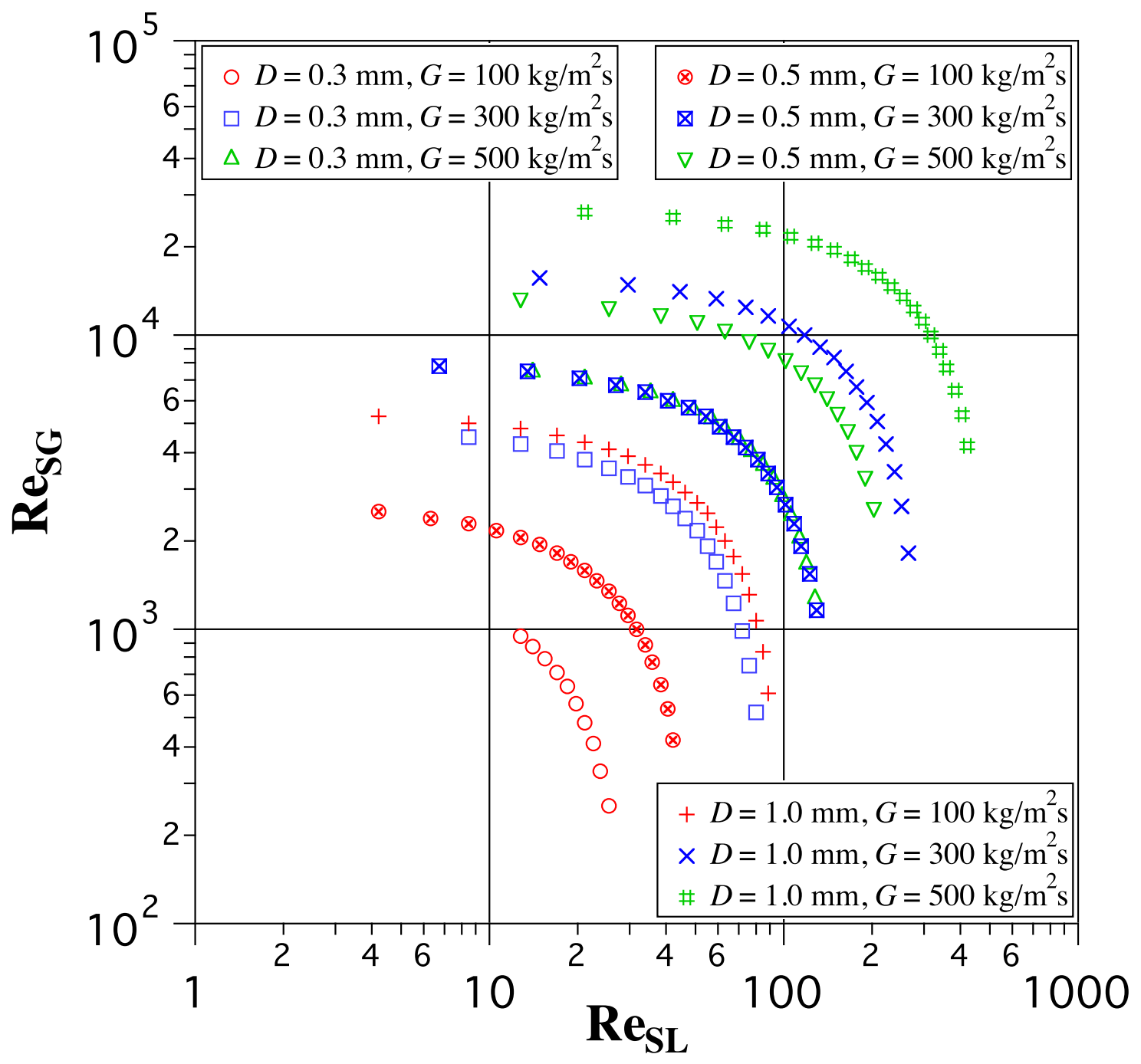

Fig. 4. Reynolds numbers based on superficial velocities of liquid and gas flows for all the experimental conditions in the present experiment 

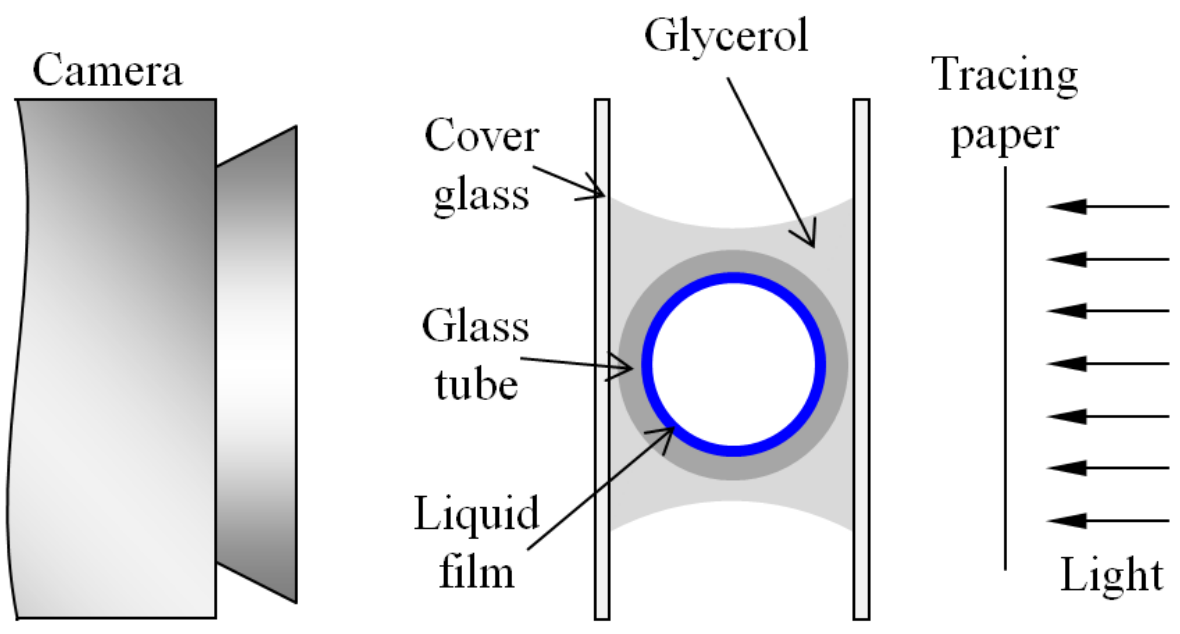

Fig. 5. Test section for high-speed camera observation 


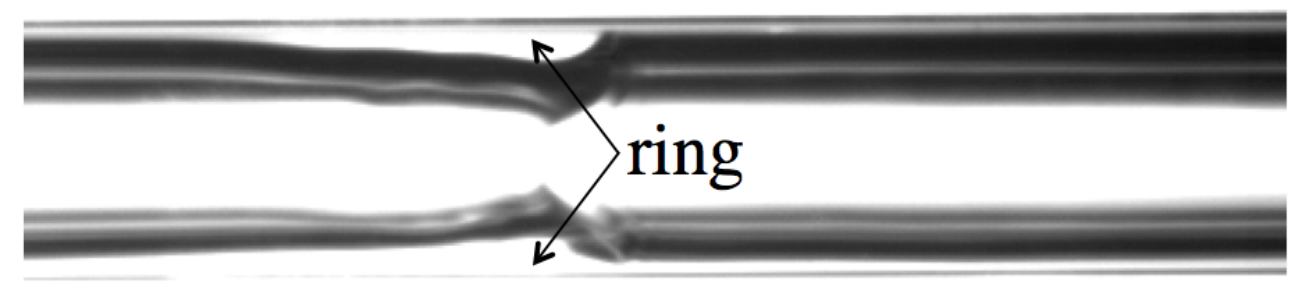

(a) $x=0.15$

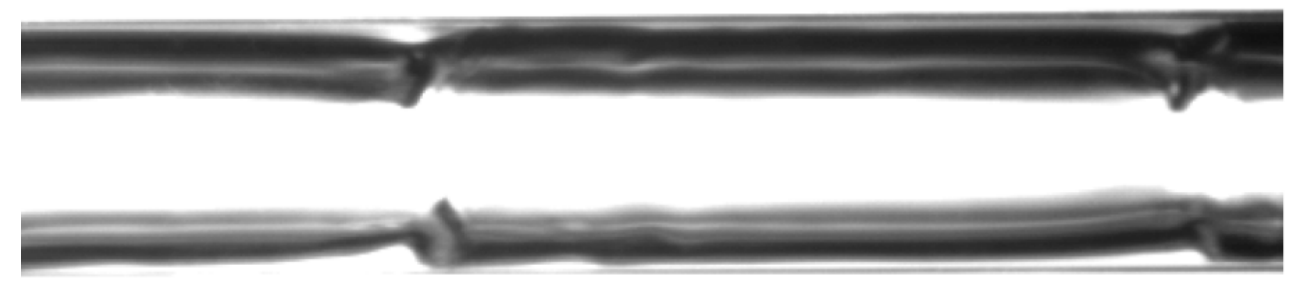

(b) $x=0.44$

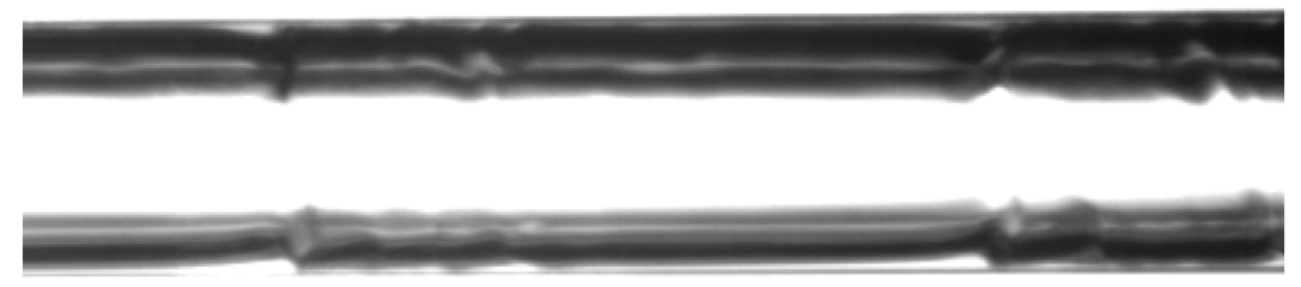

(c) $x=0.73$

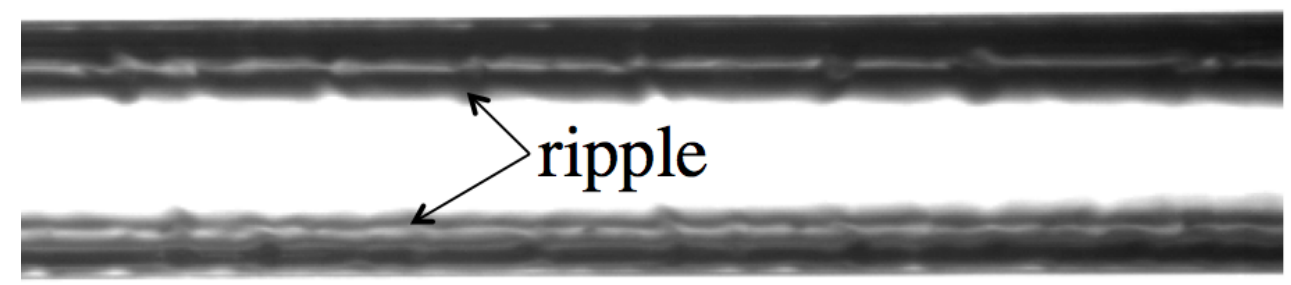

(d) $x=0.94$

Fig. 6. Flow patterns for $D=0.5 \mathrm{~mm}$ tube at $G=300 \mathrm{~kg} / \mathrm{m}^{2} \mathrm{~s}$ : (a) $x=0.15$; (b) $x=0.44$; (c) $x=0.73 ;$ (d) $x=0.94$. 


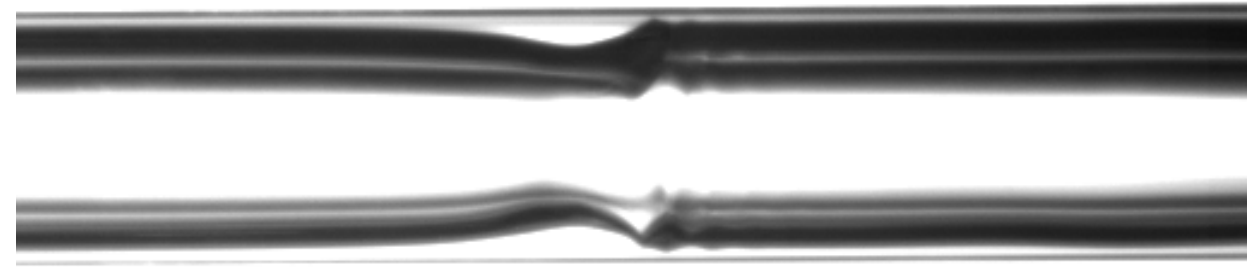

(a) $G=100 \mathrm{~kg} / \mathrm{m}^{2} \mathrm{~s}$

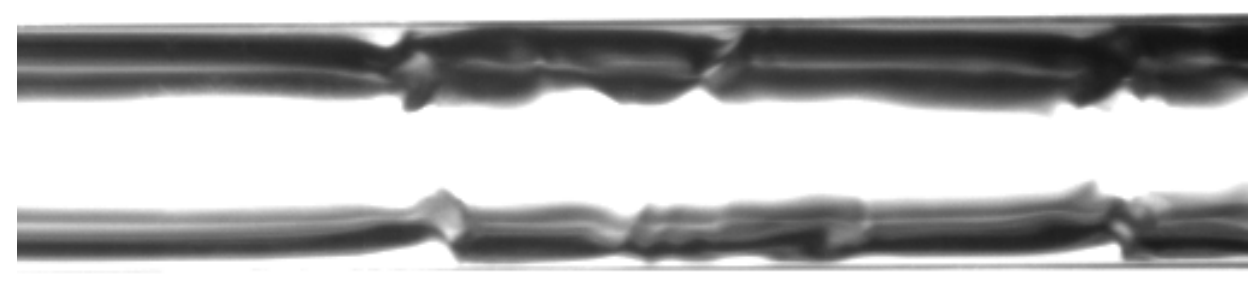

(b) $G=300 \mathrm{~kg} / \mathrm{m}^{2} \mathrm{~s}$

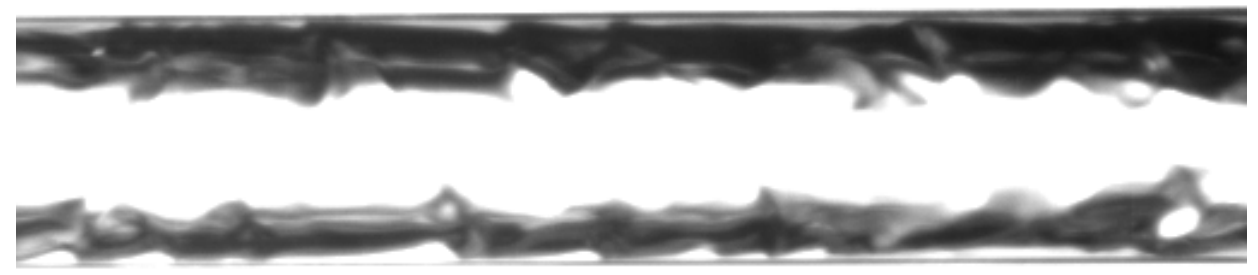

(c) $G=500 \mathrm{~kg} / \mathrm{m}^{2} \mathrm{~s}$

Fig. 7. Flow patterns for $D=0.5 \mathrm{~mm}$ tube at $x=0.45$ : (a) $G=100 \mathrm{~kg} / \mathrm{m}^{2} \mathrm{~s}$; (b) $G=300$ $\mathrm{kg} / \mathrm{m}^{2} \mathrm{~s}$; (c) $G=500 \mathrm{~kg} / \mathrm{m}^{2} \mathrm{~s}$. 
fraluris : 0

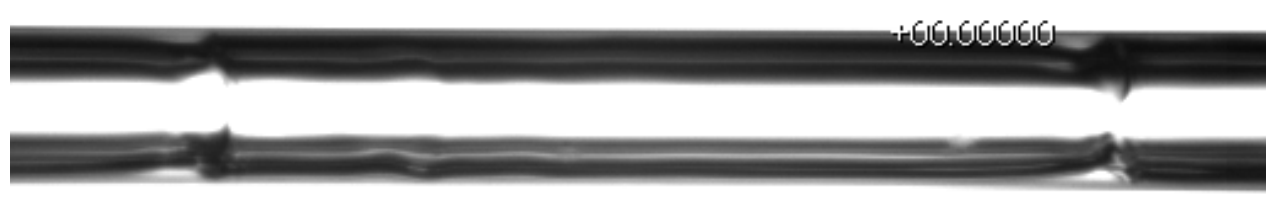

(a) $D=0.3 \mathrm{~mm}$

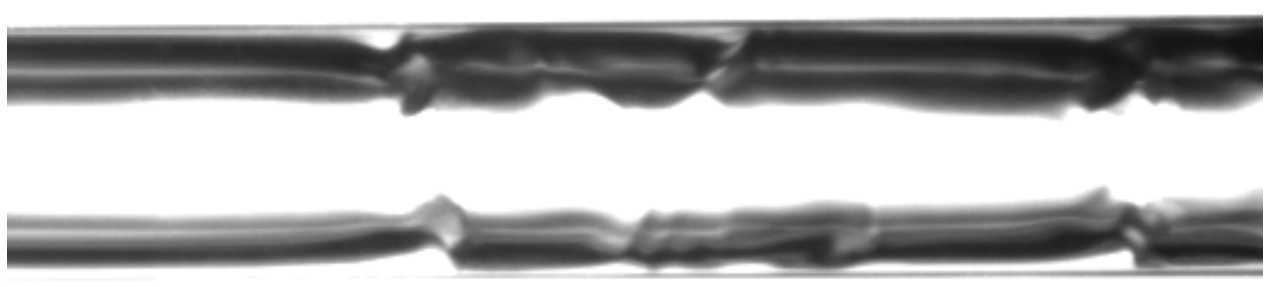

(b) $D=0.5 \mathrm{~mm}$
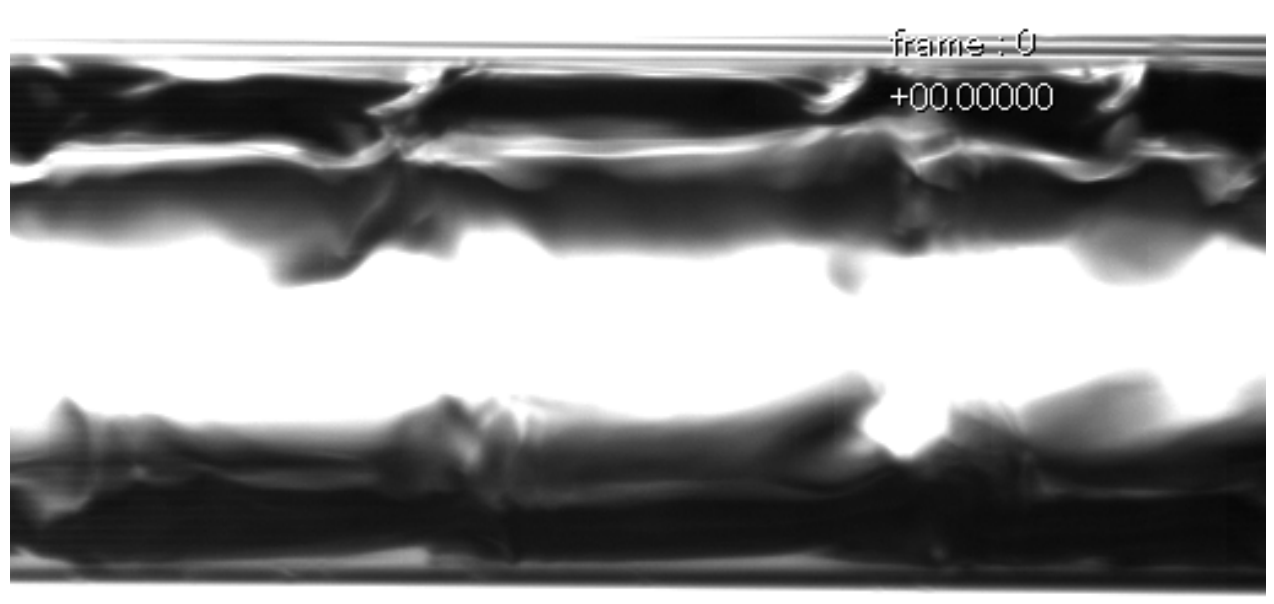

(c) $D=1.0 \mathrm{~mm}$

Fig. 8. Flow patterns at $G=300 \mathrm{~kg} / \mathrm{m}^{2} \mathrm{~s}$ and $x=0.45$ for (a) $D=0.3 \mathrm{~mm}$, (b) $D=0.5 \mathrm{~mm}$ and (c) $D=1.0 \mathrm{~mm}$ tubes. 


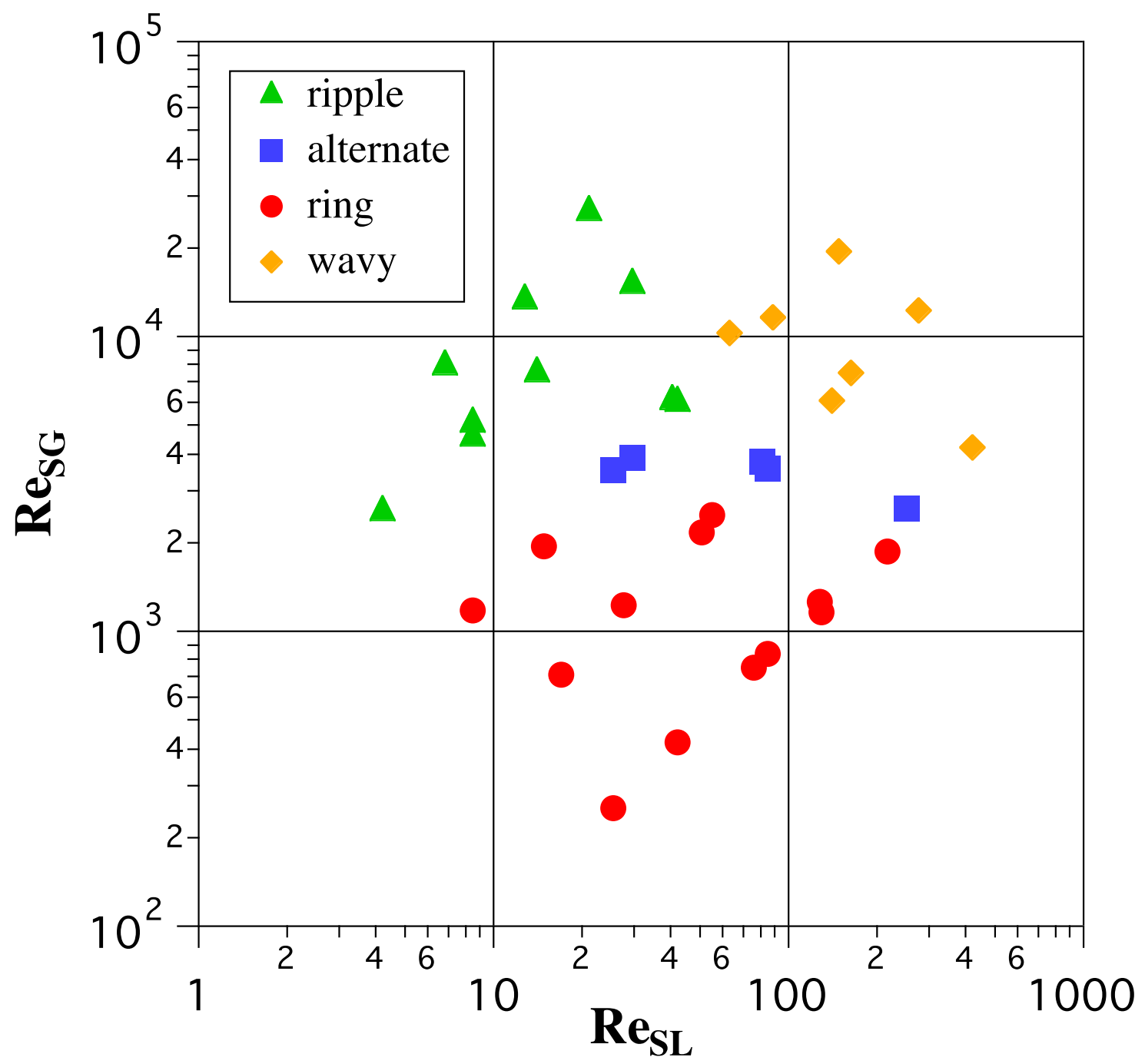

Fig. 9. Flow pattern map based on liquid and gas Reynolds numbers. 


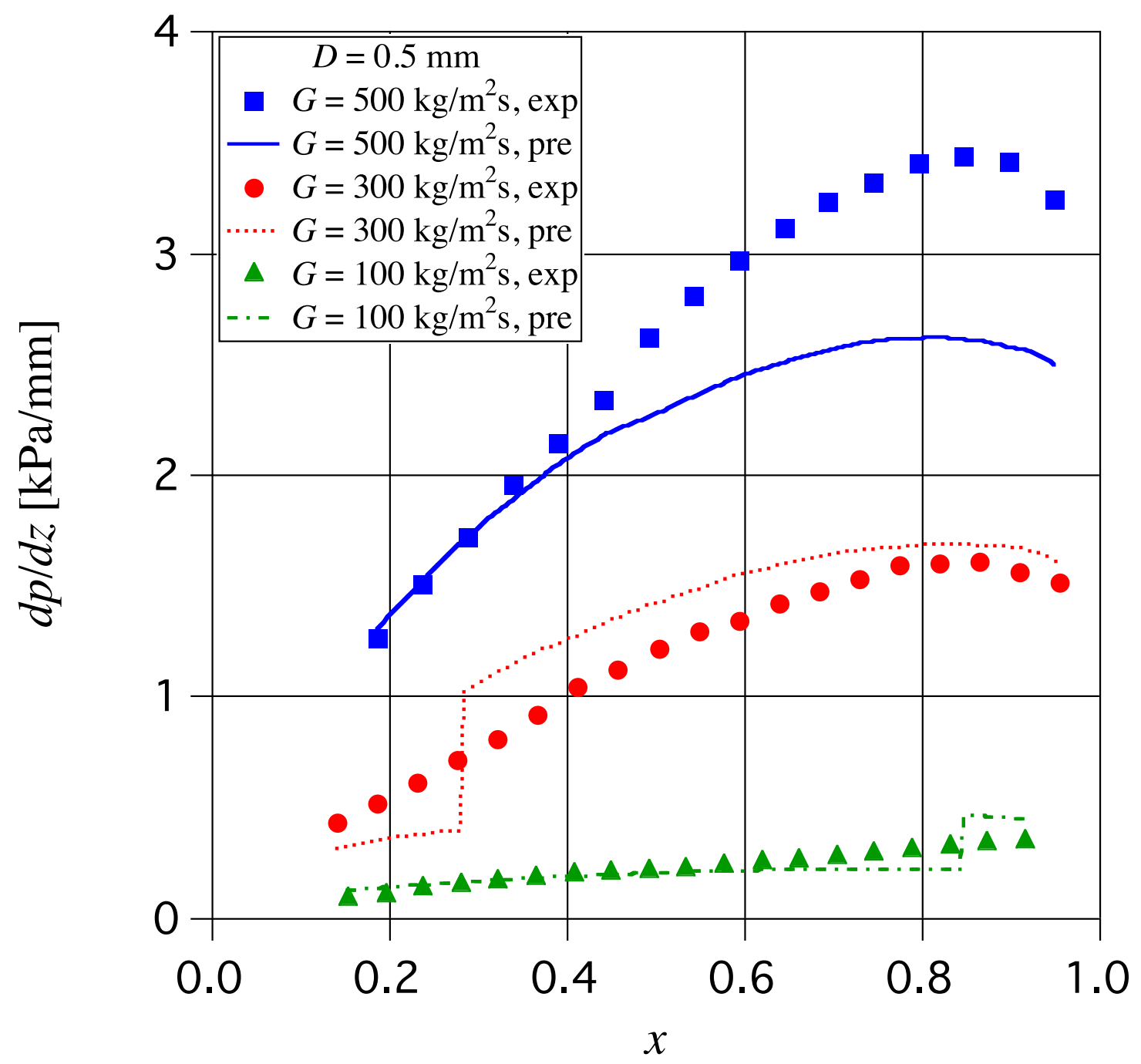

Fig. 10. Comparison between measured and predicted pressure drops in the $D=0.5 \mathrm{~mm}$ tube. 


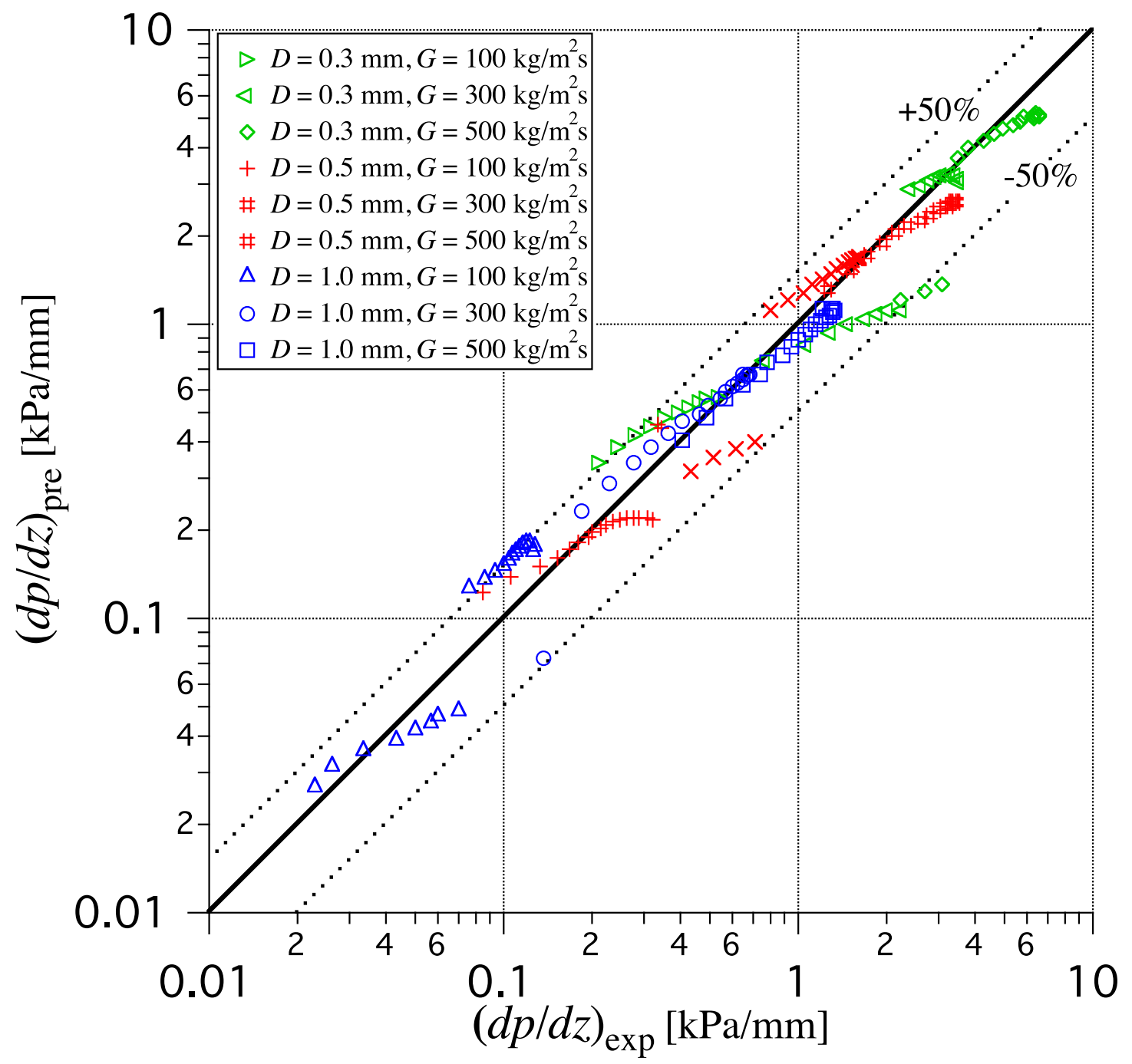

Fig. 11. Comparison between measured and predicted pressure drops with Eq. (7)-(15) for all the experimental data. 


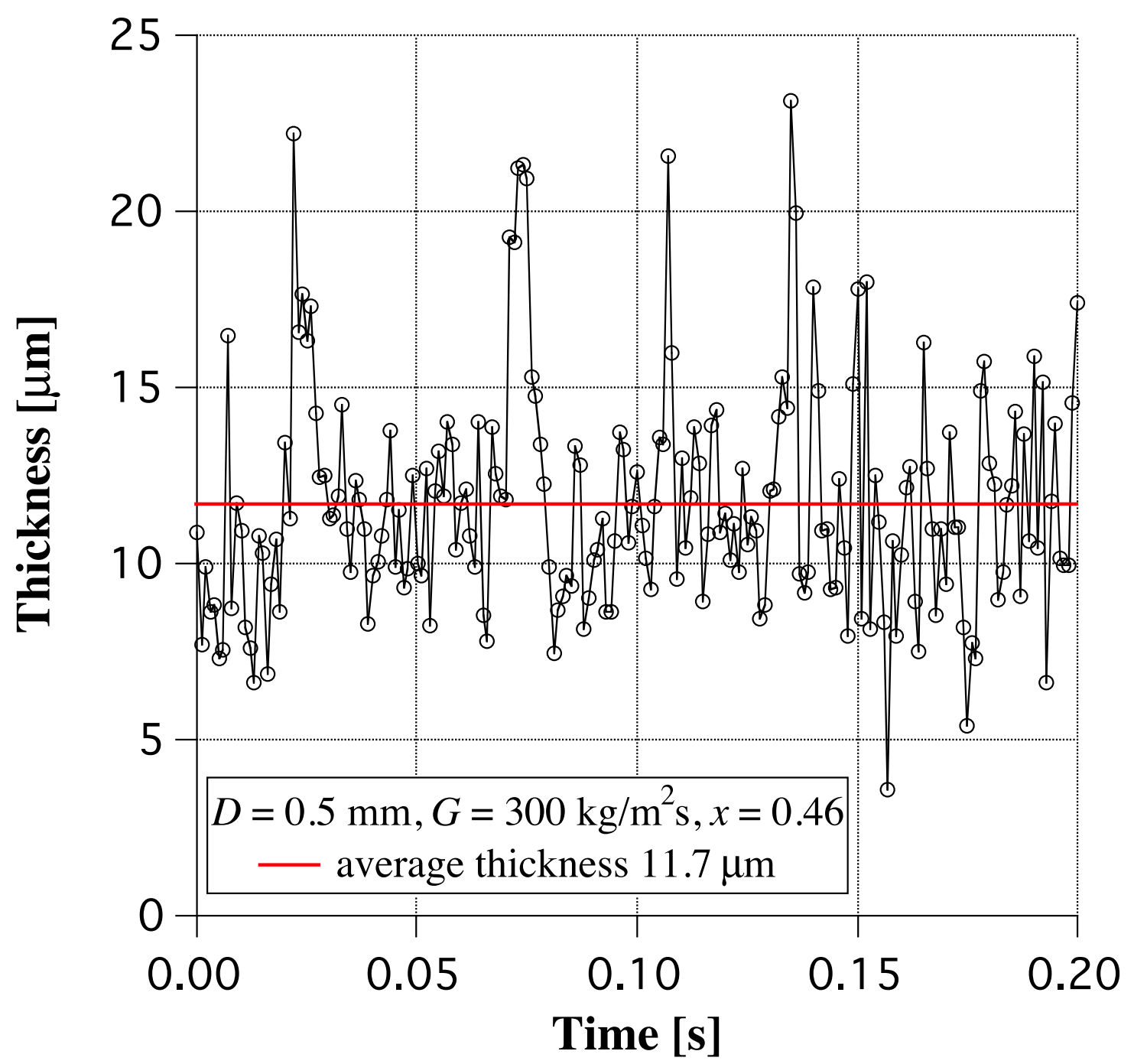

Fig. 12. Measured liquid film thickness in the $D=0.5 \mathrm{~mm}$ tube at $G=300 \mathrm{~kg} / \mathrm{m}^{2} \mathrm{~s}$ and $x=$ 0.46 . 


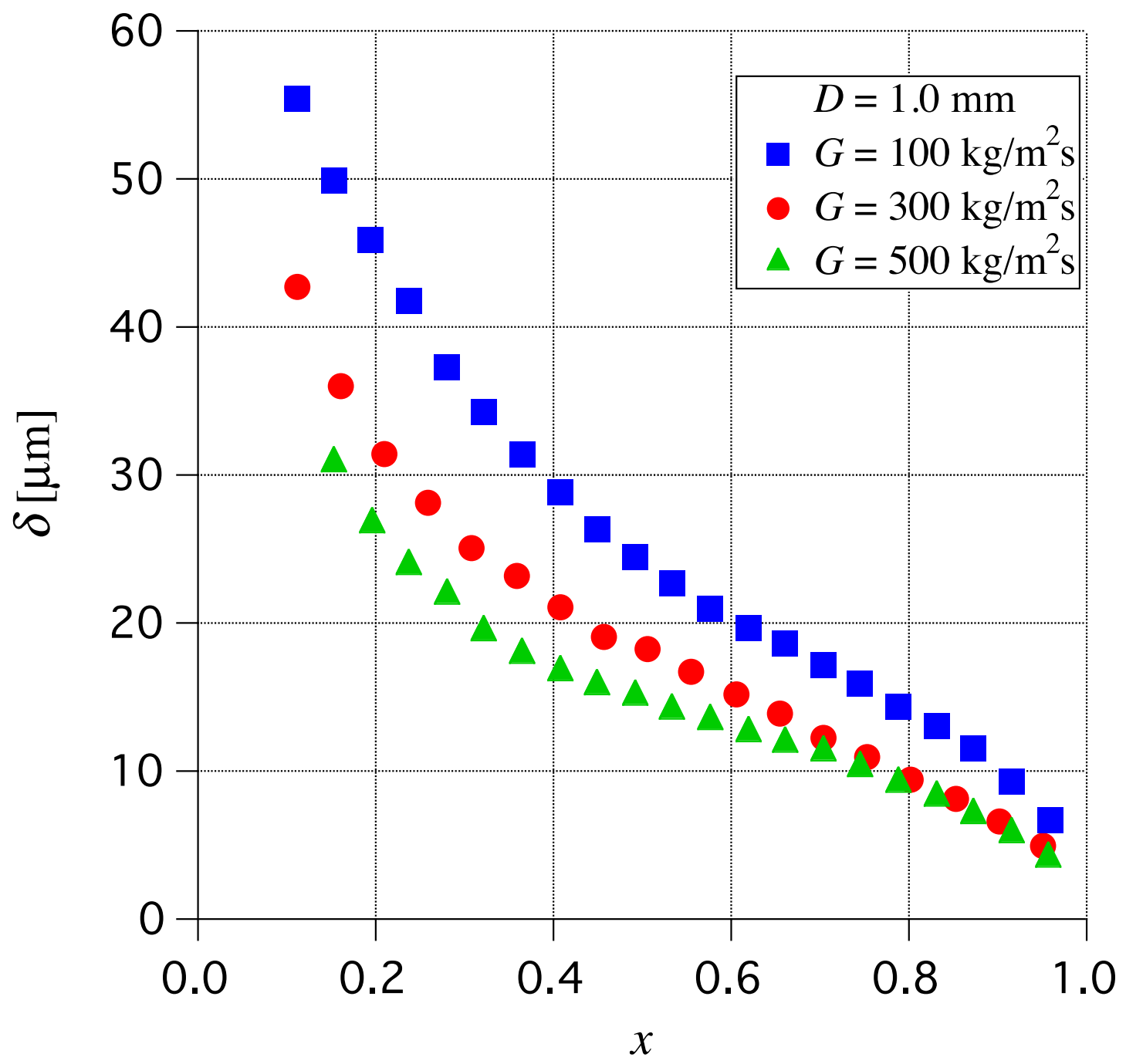

Fig. 13. Mean liquid film thickness against quality in the $D=1.0 \mathrm{~mm}$ tube. 


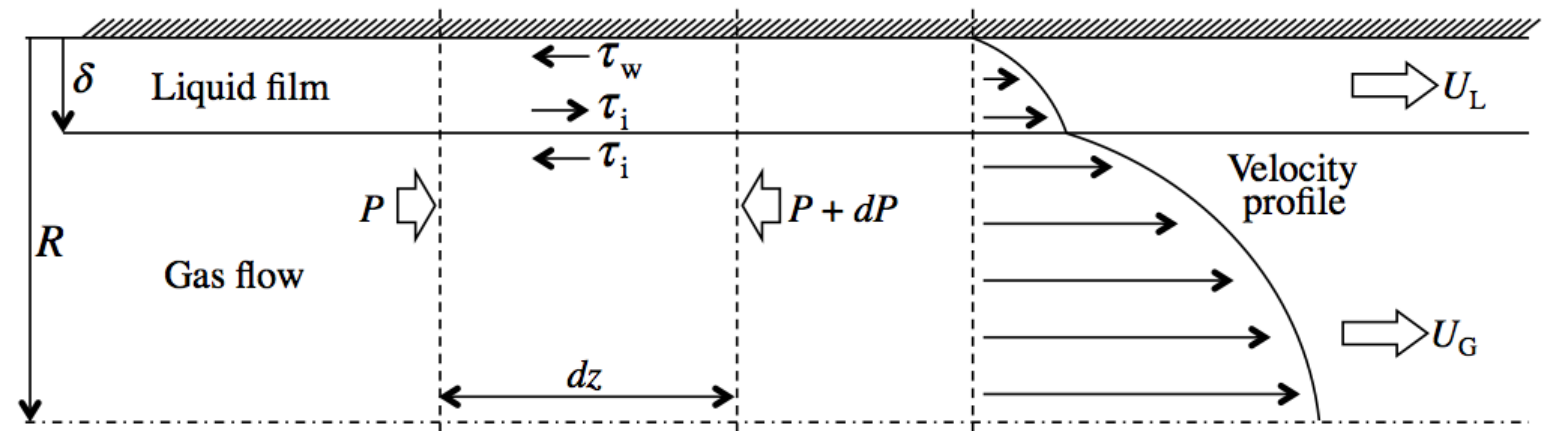

Fig. 14. Schematic diagram of the force balance in a micro tube assuming flat gas-liquid interface. 


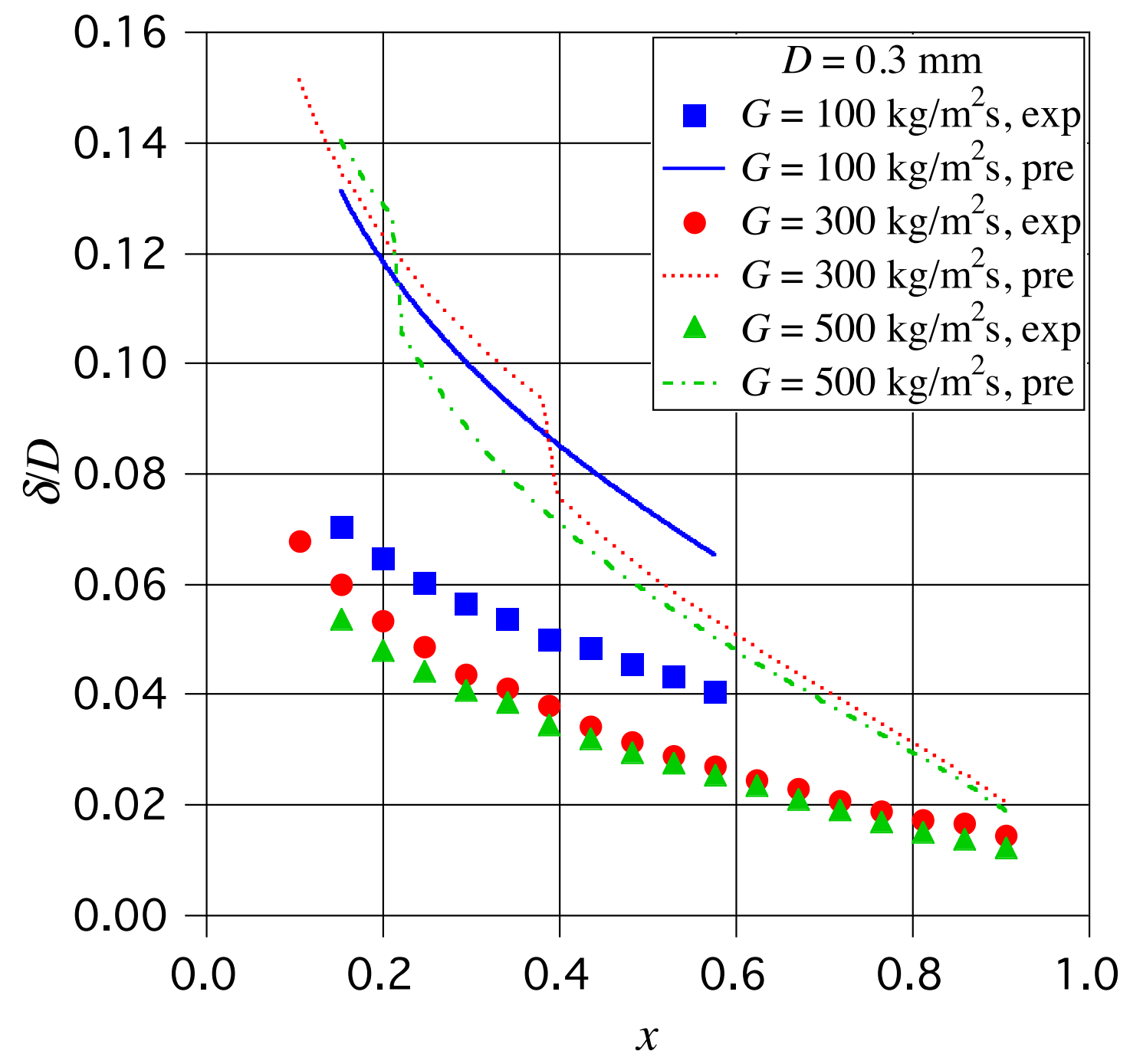

(a) $D=0.3 \mathrm{~mm}$ 


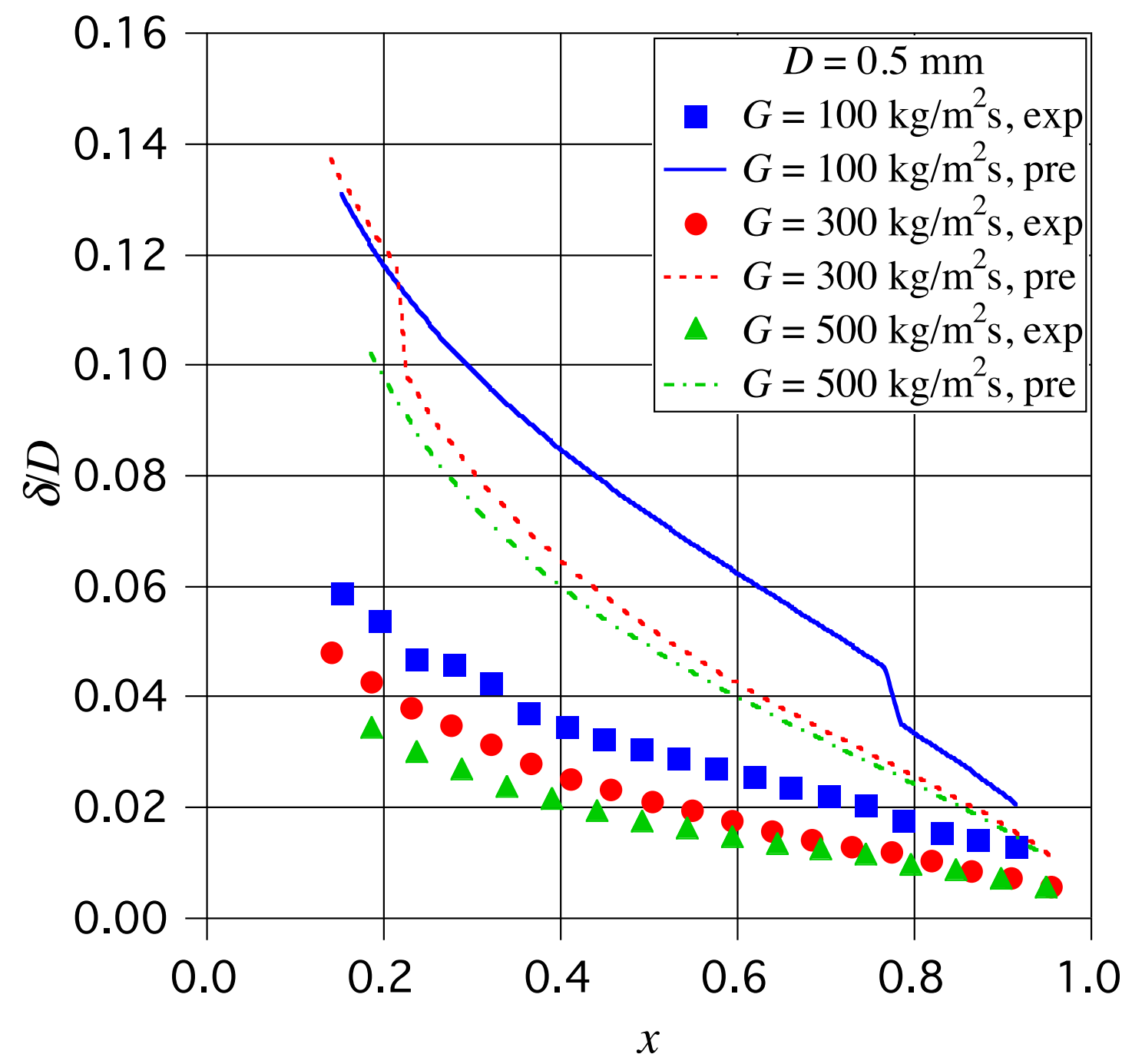

(b) $D=0.5 \mathrm{~mm}$ 


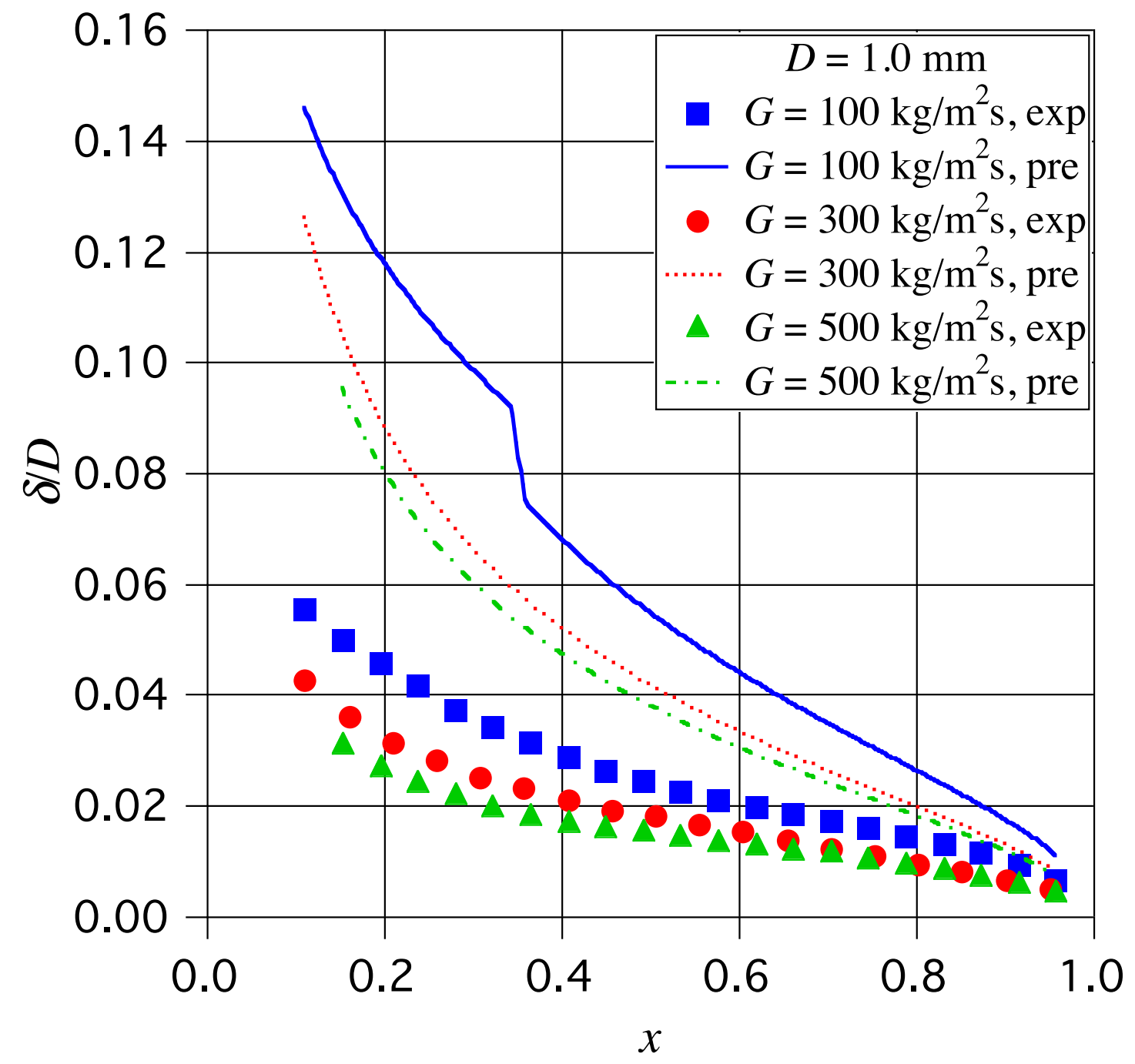

(c) $D=1.0 \mathrm{~mm}$

Fig. 15. Predicted dimensionless mean film thickness against quality using Eqs. (26)-(29) 


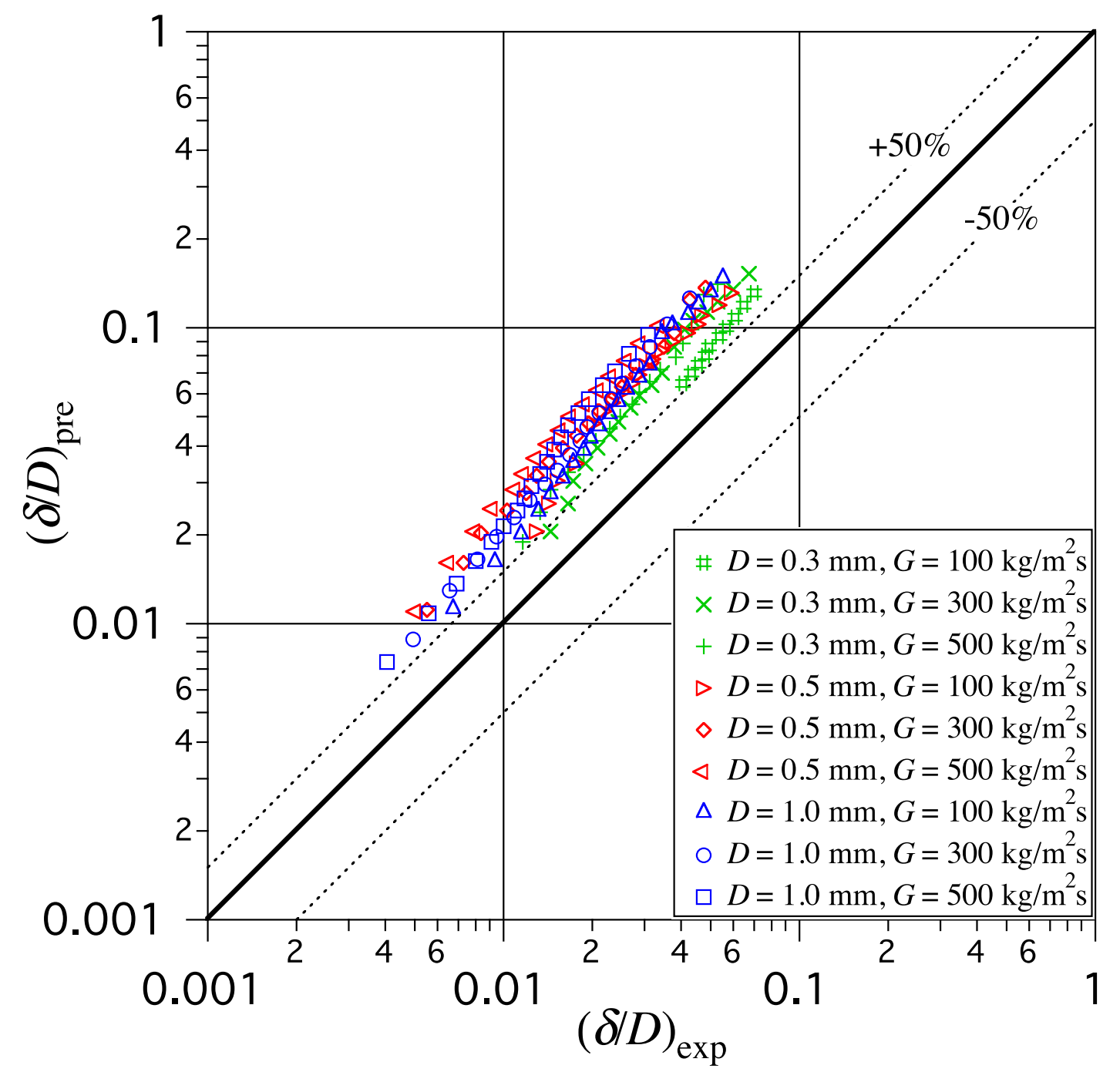

Fig. 16. Comparison between the experimental data and the prediction values using Eq. (26)-(29). 


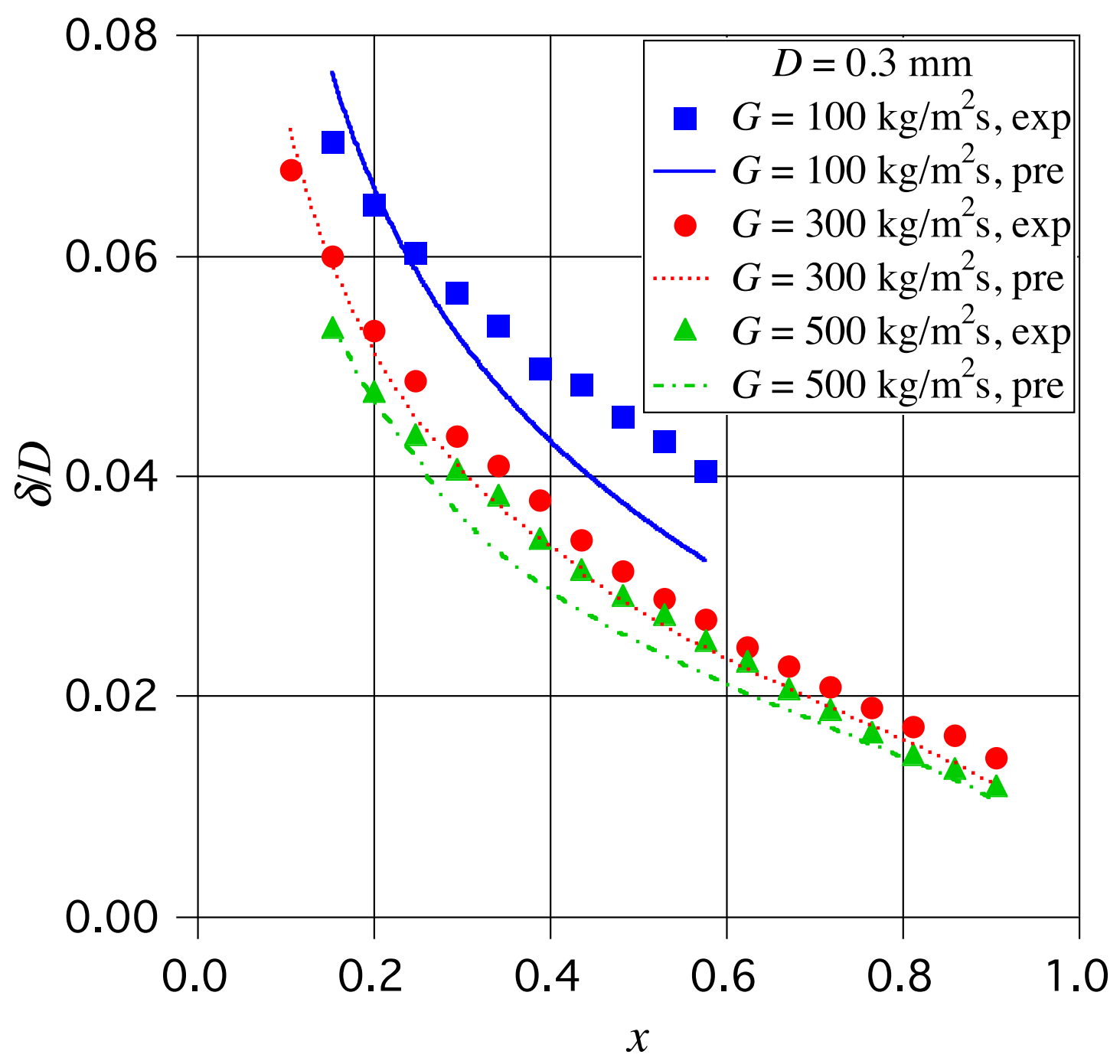

(a) $D=0.3 \mathrm{~mm}$ 


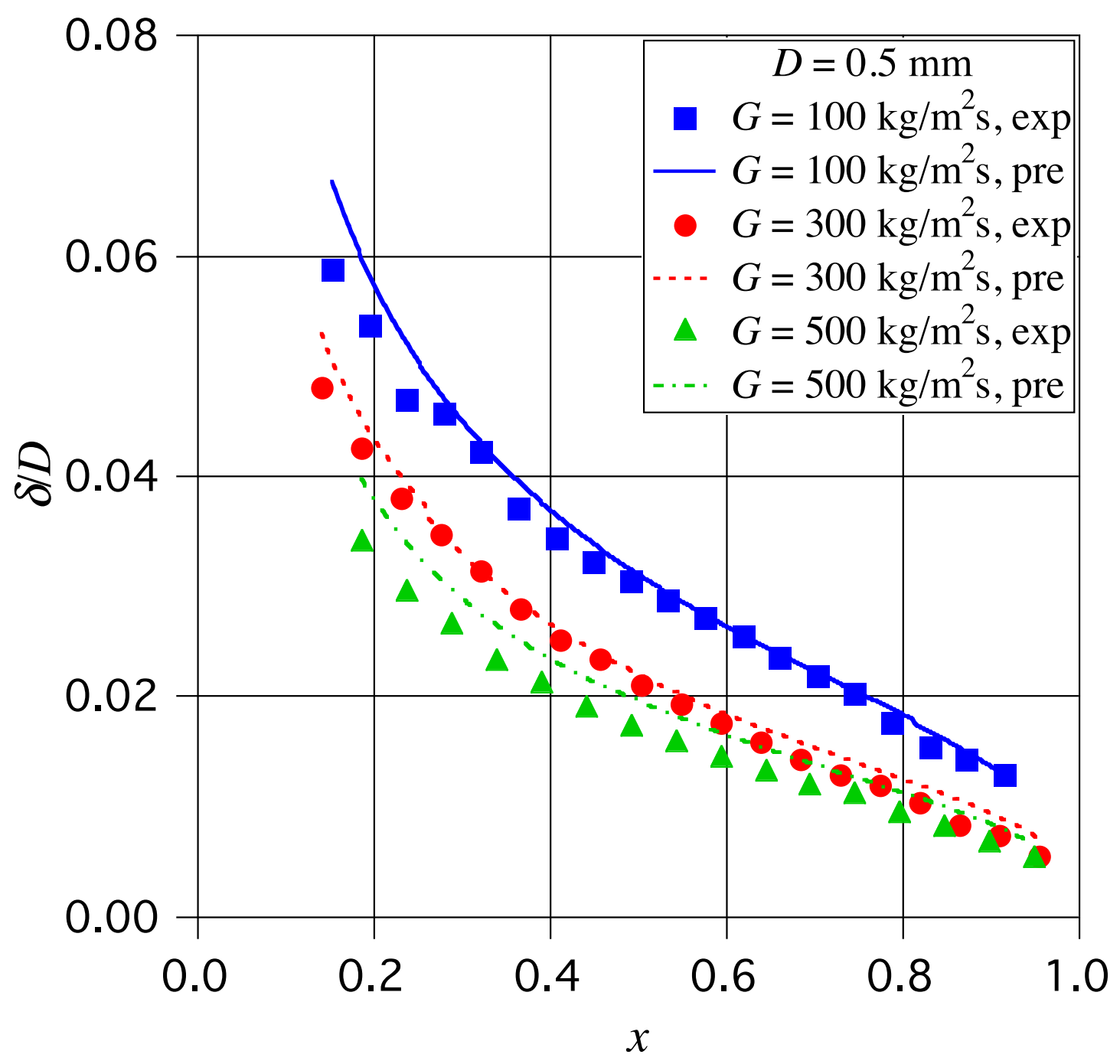

(b) $D=0.5 \mathrm{~mm}$ 


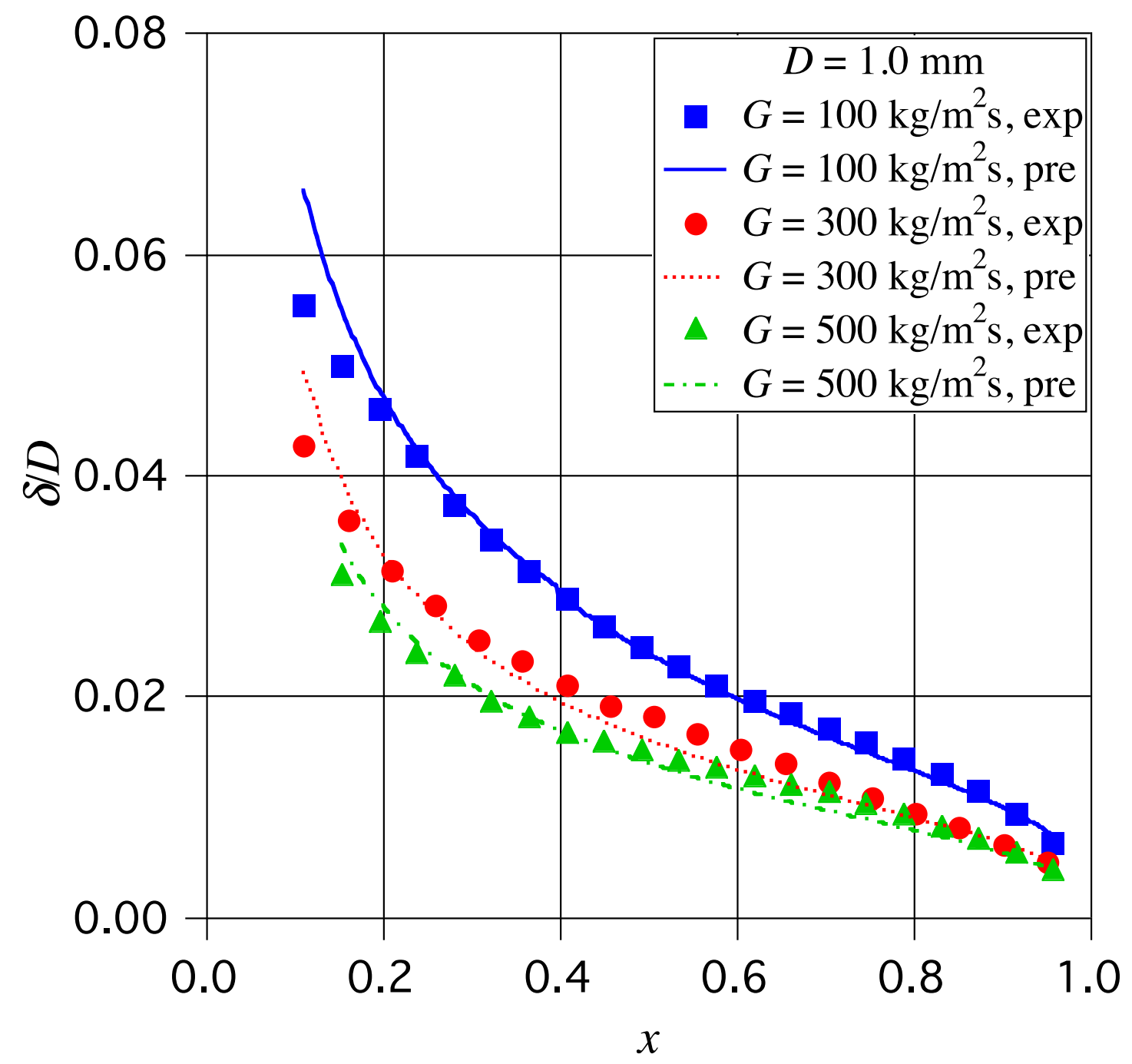

(c) $D=1.0 \mathrm{~mm}$

Fig. 17. Predicted dimensionless mean film thickness with the modified friction factor ratio, Eq. (31), 


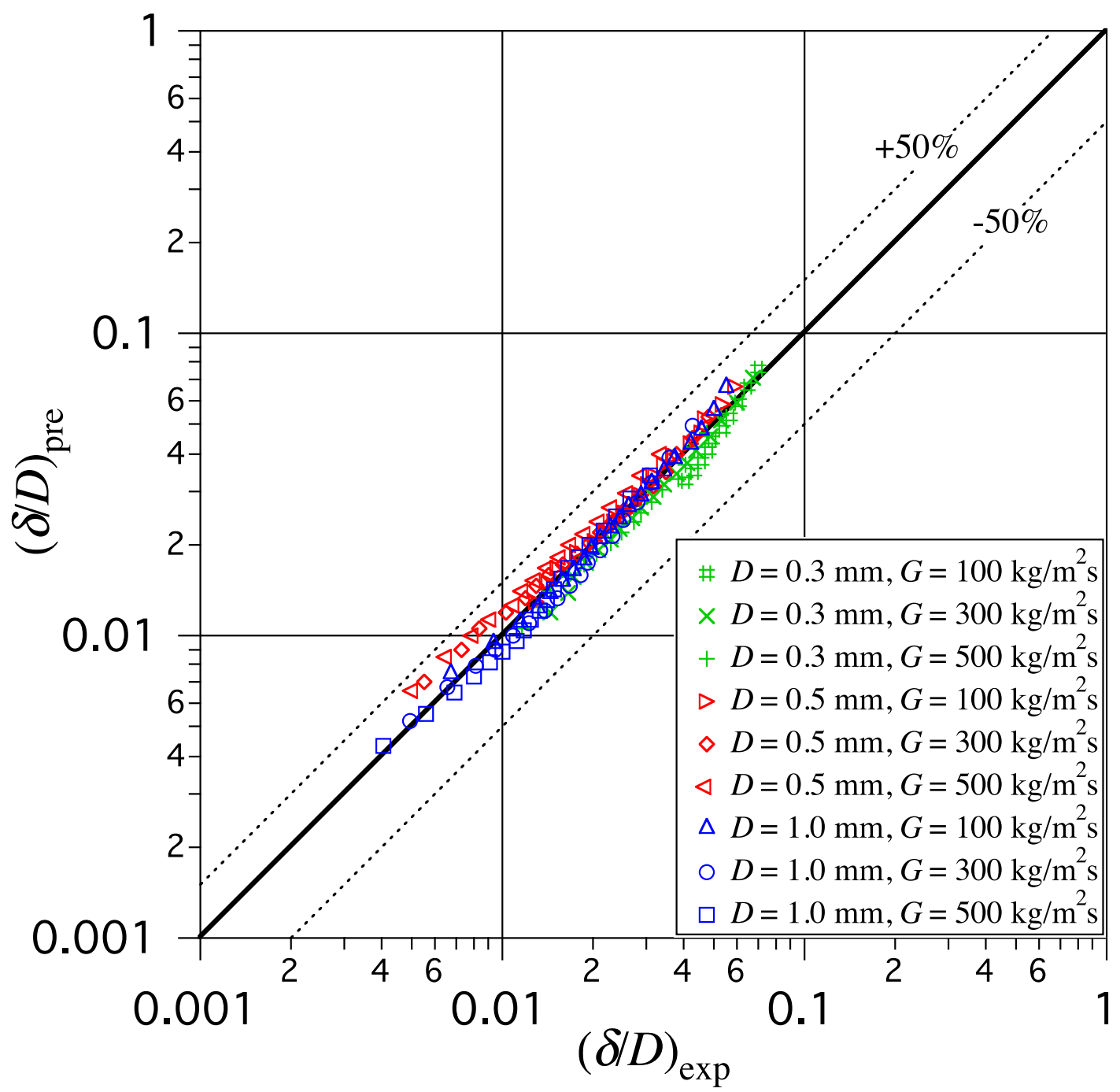

Fig. 18. Comparison the experimental data and the prediction values with the modified friction factors, Eq. (31). 


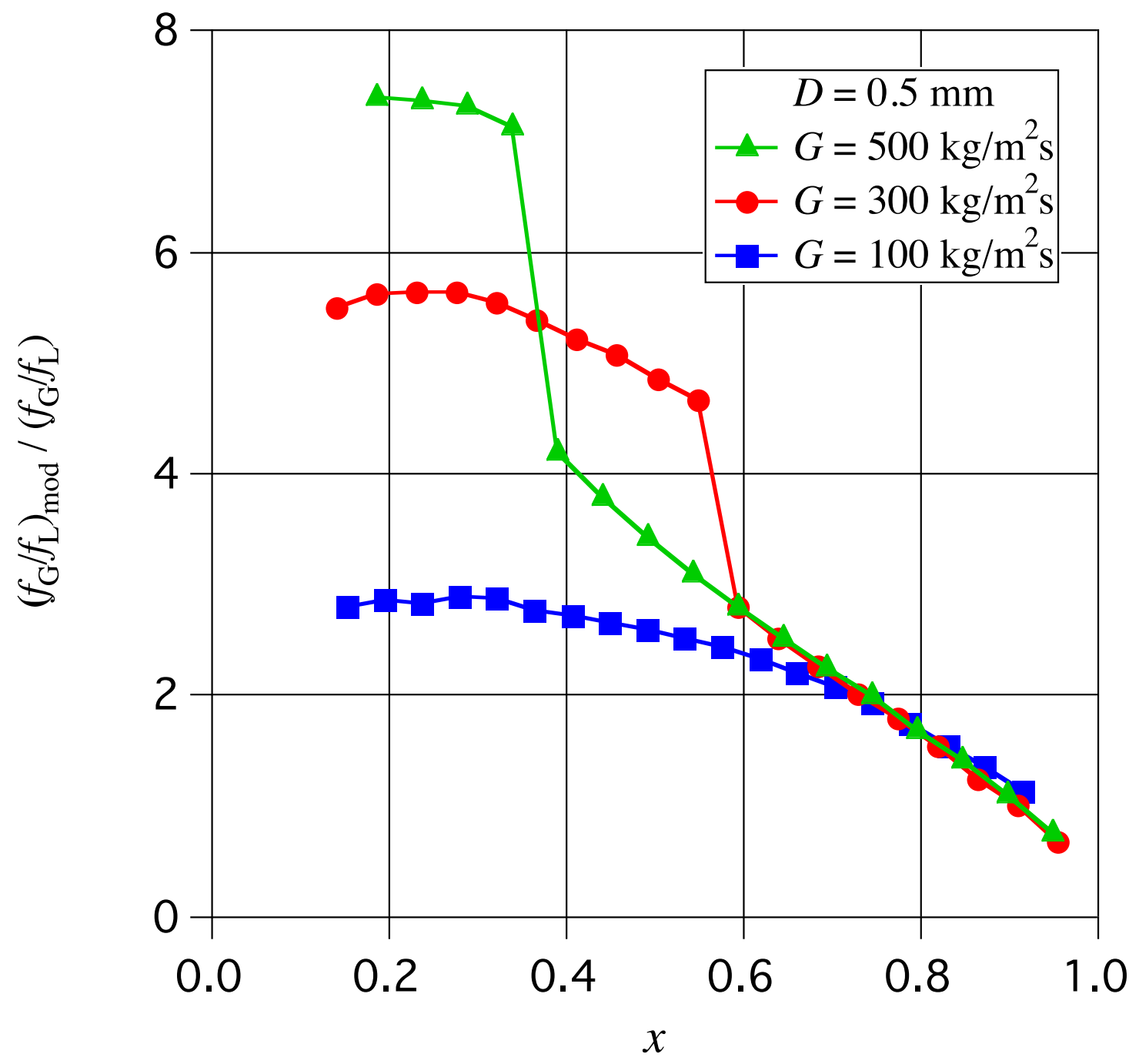

Fig. 19. Comparison between the original friction factor ratio and the modified friction factor ratio against quality in the $D=0.5 \mathrm{~mm}$ tube. 